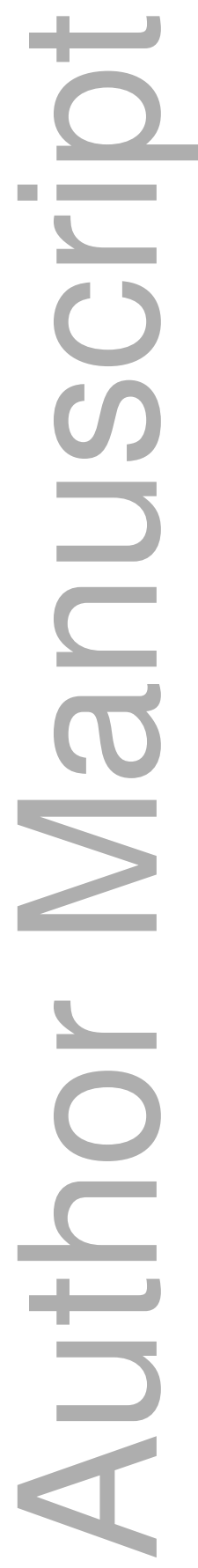

This is the author manuscript accepted for publication and has undergone full peer review but has not been through the copyediting, typesetting, pagination and proofreading process, which may lead to differences between this version and the Version of Record. Please cite this article as doi: $\underline{10.1111 / 0 B E S .12323}$

This article is protected by copyright. All rights reserved 


\title{
Economic Policy Uncertainty Spillovers in Booms and Busts*
}

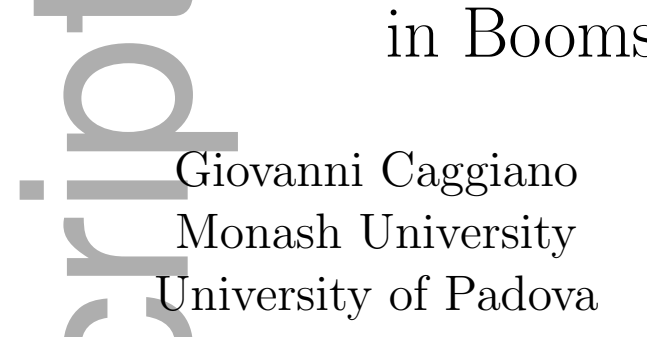

\author{
Juan Manuel Figueres \\ European Central Bank
}

March 2019

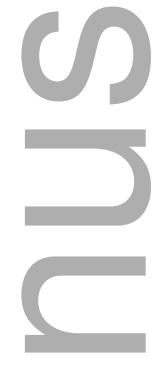

\author{
Efrem Castelnuovo \\ University of Melbourne \\ University of Padova
}

Abstract

We estimate a nonlinear VAR to quantify the impact of US economic policy uncertainty shocks on the Canadian unemployment rate in booms and busts. We find strong evidence in favor of asymmetric spillover effects. Unemployment in Canada is shown to react more strongly to uncertainty shocks in economic busts. Such shocks explain about $13 \%$ of the variance of the 2-year ahead forecast error of the Canadian unemployment rate in recessions vs. just $2 \%$ during economic booms. Counterfactual simulations point to a novel "economic policy uncertainty spillovers channel". According to this channel, jumps in US uncertainty foster economic policy uncertainty in Canada in the first place and, because of the latter, lead to a temporary increase in the Canadian unemployment rate. Evidence of asymmetric spillover effects are also found for the UK economy, whose trade intensity with the US is low. This result is consistent with a transmission channel other than trade behind our findings.

Keywords: Economic Policy Uncertainty Shocks, Spillover Effects, Unemployment Dynamics, Smooth Transition Vector AutoRegressions, Recessions.

JEL codes: C32, E32, E52.

* We thank Francesco Zanetti (Editor) and two anonymous referees for their detailed comments. We also thank Nicholas Bloom, Riccardo Colacito, Laurent Ferrara, Pedro Gomis-Porqueras, Fatih Guvenen, James Hamilton, Atanas Hristov, Alejandro Justiniano, Gunes Kamber, Ellen McGrattan, James Morley, Giovanni Pellegrino, Jeremy Piger, Daniel Rees, Barbara Rossi, Tatevik Sekhposyan, Trung Duc Tran, Dennis Wesselbaum, Wenying Yao, and participants to many workshops, conferences, and seminars for useful feedback. Financial support from the Australian Research Council - DP160102281 is gratefully acknowledged. The views expressed here are those of the authors and do not necessarily reflect the views of the European Central Bank (ECB) or the Eurosystem. Corresponding author: Efrem Castelnuovo: efrem.castelnuovo@unimelb.edu.au . 


\section{Introduction}

My view is that much of Canada's current economic policy uncertainty is due to contagion from the US. [...] Given the integrated and interdependent nature of the US and Canadian economies, this US-based economic policy uncertainty will continue to impede and adversely affect Canadian economic growth.

Nicholas Bloom, Fraser Alert, February 2013, p. 2.

Is economic policy uncertainty a driver of the business cycle? Baker, Bloom, and Davis (2016) address this question by constructing a novel index of economic policy uncertainty for the US and a number of other countries. When employing such index in VAR investigations, they find that increases in the level of uncertainty associated to policy decisions can explain a non-negligible share of the business cycle in the US and other industrialized countries. This result is important for two reasons. First, because it reaffirms that uncertainty can be one of the drivers of fluctuations in real activity in the United States, a result found by a number of authors (for recent surveys, see Bloom (2014, 2017) and Castelnuovo et al. (2017)). Second, because it points to a particular type of uncertainty - the one connected to policy decisions - as an independent source of fluctuations in real activity.

Most of the literature on uncertainty has focused on autarkic frameworks to identify the effects of an uncertainty shock. While being a natural first-step to understand the macroeconomic effects of movements in uncertainty, this assumption appears to be questionable for small-open economies, which are largely affected by shocks coming from neighboring countries and the rest of the world in general. As a matter of fact, however, little is known on the spillover effects related to second moment shocks, and in particular - economic policy uncertainty shocks. ${ }^{1}$

This paper contributes to the analysis of the transmission of second moment shocks in open economies by focusing on economic policy uncertainty spillovers from the United States to Canada. To this end, we estimate a monthly nonlinear Smooth Transition

\footnotetext{
${ }^{1}$ This paper focuses on economic policy uncertainty shocks. Proxies for conceptually different uncertainty measures have been constructed by using forecast disagreement (Bachmann, Elstner, and Sims (2013)), real GDP forecast errors (Rossi and Sekhposyan $(2015,2016)$ ), forecast errors of several macroeconomic and financial indicators (Jurado, Ludvigson, and $\mathrm{Ng}$ (2015), Carriero, Clark, and Marcellino (2018c), and Ludvigson, Ma, and Ng (2019)), Bloomberg forecasts (Scotti (2016)), interest rate data (Mumtaz and Zanetti (2013), Creal and Wu (2017) and Istrefi and Mouabbi (2017)), and Google Trends data (Castelnuovo and Tran (2017)).
} 
VAR (STVAR) model for the period 1985-2014. ${ }^{2}$ In this framework, economic policy uncertainty shocks originating in the US are allowed (but not necessarily required) to act as drivers of real activity in Canada, with possibly asymmetric effects depending on the stance of the Canadian business cycle. We model a number of Canadian macroeconomic variables, including real activity indicators (industrial production, unemployment), inflation, the policy rate, and the US-Canada bilateral real exchange rate. In computing the effects of US EPU shocks on the Canadian economy, we control for the Canadian EPU index, so that uncertainty shocks originating in the US can affect the Canadian economy via uncertainty spillovers. ${ }^{3}$ Notice that a jump in policy-related US uncertainty is potentially recessionary, and can in principle lead the Canadian economy to switch from - say - a boom to a bust. As a consequence, modeling absorbing states and estimating conditionally linear impulse responses would likely lead to biased results. Our analysis accounts for the possible transition from a state of the economy to another by computing Generalized Impulse Response Functions (GIRFs) à la Koop, Pesaran, and Potter (1996). This modeling choice implies that the probability of being in a given state of the business cycle is a fully endogenous object in our framework. Notably, US EPU shocks are identified by assuming that they cannot contemporaneously respond to developments in the Canadian economy. This assumption is consistent with (in fact, it is weaker than) the usually imposed block exogeneity assumption when dealing with the US-Canada economic relationships (see, e.g., Justiniano and Preston (2010)). Moreover, this is also consistent with some recent findings pointing to macroeconomic uncertainty being exogenous with respect to the business cycle (Carriero, Clark, and Marcellino (2018b)).

We find statistically and economically relevant nonlinear spillover effects. An economic policy uncertainty hike originating in the US is estimated to trigger a strong and

\footnotetext{
${ }^{2}$ The measures of EPU we use for Canada and, in a related exercise reported in Section 7, for the UK are based on information contained in newspapers only. When we started this project, such a measure for the US was available only until October 2014. This series is now constantly updated and available at http://www.policyuncertainty.com/. However, our nonlinear analysis requires enough observations in both states (recessions and expansions) for econometric identification to be achieved. Extending the sample to 2018 adds observations in one regime only (expansions), and renders our nonlinear analysis less reliable. Section 3 further elaborates on this point. We anticipate that a robustness check (documented in our Appendix) conducted with the 1985-2018 sample returns very similar results with respect to those documented in this paper.

${ }^{3}$ Our baseline model assumes that economic policy uncertainty cannot contemporaneously respond to developments in the economy. A discussion on the reasons behind this identification scheme is provided in Section 2. We anticipate that: i) our results are robust to putting the US and Canadian EPU indices last in the vector; ii) a recent paper by Carriero, Clark, and Marcellino (2018b) finds macroeconomic uncertainty to not be contemporaneously affected by the business cycle.
} 
persistent downturn in Canada in the 1985-2014 period during bad economic times. An equally-sized shock, when occurring in booms, leads to quantitatively milder and mostly insignificant responses of real activity indicators. Monetary policy reacts by lowering the interest rate much more in bad than in good times. A forecast error variance decomposition exercise confirms that contagion via uncertainty shocks is a quantitatively more relevant phenomenon when Canada's growth rate is below trend. In particular, uncertainty shocks originating in the US explain up to $13 \%$ of the variance of the 2 -year ahead forecast error of the Canadian unemployment rate during slow-growth phases vs. about $2 \%$ during economic booms.

One of the variables reacting in a significant and persistent fashion to US EPU shocks is the Canadian EPU index. We analyze the role played by the evolution of the latter in the transmission of US EPU shocks to the Canadian economy vis-à-vis the role played by bilateral trade by estimating a version of the STVAR model that features Canadian net exports to the United States. Focusing on economic busts, we then conduct two counterfactual exercises to simulate the response of unemployment in Canada to a US EPU shock when: i) the Canadian EPU index is not allowed to react to systematic movements in US economic policy uncertainty, and ii) net exports do not react to US EPU. The response of the Canadian unemployment rate turns out to be dramatically dampened only in the counterfactual scenario where the response of Canada EPU is muted, while it is virtually unchanged relative to the baseline case in the scenario of a muted response of net exports. Such findings point to the existence of a novel "economic policy uncertainty spillover channel": hikes in the level of the US economic policy uncertainty foster the build up of EPU in Canada and, consequently, exert a negative effect on the Canadian business cycle. To reinforce the evidence that the main transmission channel of US EPU shocks to other economies is not related to trade, we conduct a similar exercise for the UK, a large open economy with a relatively low degree of trade intensity with the United States. ${ }^{4}$ Again, we find that US EPU shocks generate significant real effects that are asymmetric over the business cycle. We interpret this result as pointing to the relevance of channels alternative to the standard trade-related one for the international transmission of US EPU shocks.

We focus on US and Canada to investigate whether economic policy uncertainty originating in a large country can affect, and via which mechanism, business cycle fluctuations in a smaller open economy for three main reasons. First, the degree of

\footnotetext{
${ }^{4}$ In 2014 , the share of total UK exports imported by the US was $11 \%$, while a share equal to $6.7 \%$ of total UK imports was coming from the US. In 1985, the shares were $16 \%$ and $11 \%$, respectively.
} 
interconnection between the US and Canada is high. According to the Observatory of Economic Complexity (OEC), $74 \%$ of Canadian total exports were imported by the United States, and 55\% of Canadian imports came from the United States in 2014, the end year of our sample. ${ }^{5}$ Second, first-moment shocks like technology, monetary policy, and fiscal shocks originating in the United States are typically found to explain a sizeable fraction of the yolatility of real activity in Canada (see, among others, Schmitt-Grohe (1998), Justiniano and Preston (2010), Kulish and Rees (2011), Faccini, Mumtaz, and Surico (2016), Ong (2018)). For instance, Justiniano and Preston (2010) document that $52 \%$ of 2 year-ahead Canadian output growth volatility is explained by first-moment US shocks. Our paper complements these contributions by focusing on US economic policy uncertainty shocks, which are second-moment shocks. ${ }^{6}$ Third, as pointed out by Bloom (2017), small open economies like Canada are likely to be hit by large uncertainty shocks that have a foreign origin, and they can be claimed to be unrelated to the domestic business cycle and, therefore, exogenous. Hence, small open economies like Canada are the ideal laboratory to identify the causal link going from uncertainty to real activity.

Our analysis focuses mainly on the possibly asymmetric response of unemployment, which can be due to downward wage rigidity (Benigno and Ricci (2011)), possibly in presence of deviations from an efficient wage-setting due to matching frictions in the labor market (Cacciatore and Ravenna (2018)). Evidence pointing to an asymmetric behavior of the unemployment rate is provided by, among others, Koop and Potter (1999), van Dijk, Tersvirta, and Franses (2002), Morley and Piger (2012), and Morley, Piger, and Tien (2013) for the US, and Dibooglu and Enders (2001) for Canada. Moreover, uncertainty dramatically increases during economic downturns (Jurado, Ludvigson, and Ng (2015), Bloom, Floetotto, Jaimovich, Saporta-Eksten, and Terry (2018), Angelini, Bacchiocchi, Caggiano, and Fanelli (2019)), a countercyclical behavior which is featured also by unemployment. Hence, the effects triggered by uncertainty shocks in recessions are likely to be different than those occurring in expansions. Recent evidence on the US

\footnotetext{
${ }^{5}$ In 1985 , the initial year of our analysis, these ratios were $77 \%$ and $72 \%$, respectively. Data available at http://atlas.media.mit.edu/en/ .

${ }^{6}$ As correctly pointed out by an anonymous referee, uncertainty enters and impacts the conditional mean (as opposed to the conditional variance) of our VAR. Hence, it is technically modeled as a firstmoment shock. We argue that it can be interpreted as a second moment shock in a VAR capturing the impact of such shock on the policy functions of an unknown nonlinear DSGE framework. An example in the literature is provided by Basu and Bundick (2017). They show that the macroeconomic responses to an uncertainty shock in their nonlinear DSGE model can be well approximated by a linear VAR framework. We interpret our impulse responses as related to a nonlinear DSGE framework differently calibrated in recessions and expansions and/or featuring an endogenous mechanism which allows economic policy uncertainty shocks to trigger a transition from a state of the economy to another.
} 
economy along this line is provided by, among others, Nodari (2014), Caggiano, Castelnuovo, and Groshenny (2014), Caggiano, Castelnuovo, and Figueres (2017), Caggiano, Castelnuovo, and Nodari (2019) and Ferrara and Gurin (2018), while Casarin, Foroni, Marcellino, and Ravazzolo (2018) find evidence in favor of state-dependent uncertaintyrelated coefficients in a panel approach modeling the US, a number of European countries, and Japan.

Our paper relates to other contributions which have investigated the role of uncertainty shocks in an open economy context. Working with microfounded DSGE frameworks, Fernndez-Villaverde, Guerrón-Quintana, Rubio-Ramírez, and Uribe (2011), Born and Pfeifer (2014), Gourio, Siemer, and Verdelhan (2013), Benigno, Benigno, and Nistic (2012), and Mumtaz and Theodoridis (2015) find different forms of volatility or uncertainty to be relevant for the open economies they model. This finding is corroborated by Born, Mller, and Pfeifer (2013), Handley (2014) and Handley and Limão (2015, 2017), whose focus is on the link between policy uncertainty, trade, and real activity. Turning to time series analysis, Berger, Grabert, and Kempa (2016) employ a dynamic factor model and estimate the stochastic volatility associated to a global factor (as opposed to that of country-specific ones), which they interpret as a measure of global uncertainty in a panel of 20 OECD countries. They find the contribution of global uncertainty shocks to the dynamics of inflation and output growth in these countries to be significantly larger than that of idiosyncratic disturbances to uncertainty. Belke and Osowski (2018) estimate a large-scale factor-augmented vector autoregressive model for 18 OECD countries. They find evidence in favor of sizeable cross-border effects related to EPU shocks. Working with a VAR framework, Colombo (2013) studies the spillover effects of an economic policy uncertainty shock originating in the United States for the Euro area. She finds such shocks to be an important driver of the European policy rate. Carrire-Swallow and Cspedes (2013) study the impact of uncertainty shocks originating in the US on a number of developed and developing countries. They find substantial heterogeneity in the response of investment and consumption across countries. In particular, the response is more accentuated in developing countries, a stylized fact which the authors interpret in light of the different credit frictions affecting the functioning of financial markets in the countries under scrutiny. Cesa-Bianchi, Pesaran, and Rebucci (2018) employ a Global-VAR approach to study the effects of hikes in volatility on real activity for a number of industrialized and developing countries. They find the role of uncertainty shocks to be modest. Klößner and Sekkel (2014) study international spillovers of policy uncertainty and find evidence in favor of economic policy uncer- 
tainty connectedness for a number of countries, with the US being the main exporter of policy uncertainty. Carriero, Clark, and Marcellino (2018a) employ large scale VAR frameworks to jointly estimate novel measures of macroeconomic uncertainty and quantify the impact of global uncertainty shocks for 19 industrialized countries. They find uncertainty shocks to negatively affect the business cycle and the stock market across the board. Our paper adds to this literature by unveiling the nonlinear effects that economic policy uncertainty shocks originating in the US exert as regards the Canadian business cycle. $^{7}$

The structure of the paper is the following. Section 2 details our empirical set up. In particular, it discusses the identification of an US EPU-related uncertainty shock and presents the Smooth Transition VAR model we employ in our analysis. Section 3 presents the estimated dynamics responses of the Canadian economy to economic policy uncertainty spillovers coming from the United States. A list of robustness checks, which confirm the baseline results, are documented in Section 4. Section 5 looks at the importance of EPU shocks for the Canadian business cycle by reporting FEVD, and documents the existence of an "economic policy uncertainty spillover" channel. Section 6 extends our analysis to the United Kingdom. Section 7 concludes.

\section{Modeling asymmetric spillover effects: Shocks and dynamics}

The Economic Policy Uncertainty index. As anticipated in the Introduction, we use the index developed by Baker, Bloom, and Davis (2016) for the US and Canada as proxies of economic policy-related uncertainty. This index is based on newspaper coverage frequency. As regards the United States, they use two overlapping sets of newspapers. The first spans the 1900-1985 period and comprises The Wall Street Journal, The New York Times, The Washington Post, The Chicago Tribune, The Los Angeles Times, and The Boston Globe. Since 1985, USA Today, The Miami Herald, The Dallas Morning Tribune, and The San Francisco Chronicle have been added to the set. The authors perform within-month searches of all articles, starting in January 1900, for terms related to economic and policy uncertainty. In particular, they search for articles containing the term "uncertainty" or "uncertain", the terms "economic", "economy", "business", "commerce", "industry", and "industrial", and the terms: "congress", "leg-

\footnotetext{
${ }^{7} \mathrm{~A}$ more extensive literature review can be found in Caggiano, Castelnuovo, and Figueres (2018) (the working paper version of this paper).
} 
islation", "white house", "regulation", "federal reserve", "deficit", "tariff", or "war". The article is included in the count if it features terms in all three categories pertaining to uncertainty, the economy and policy. To deal with changing volumes of news articles for a given newspaper over time, Baker, Bloom, and Davis (2016) divide the raw counts of policy uncertainty articles by the total number of news articles containing terms regarding the economy or business. They then normalize each newspaper's series to unit standard deviation prior to December 2009 and then sum up all series. Details are reported in Baker, Bloom, and Davis (2016).

We now turn to the description of the nonlinear model we employ in our empirical analysis.

STVAR model. We allow for asymmetric spillover effects by modeling Canadian macroeconomic indicators with a Smooth-Transition VAR framework (for a reference textbook, see Tersvirta, Tjstheim, and Granger (2010)). Formally, our STVAR model reads as follows:

$$
\begin{aligned}
\boldsymbol{X}_{t} & =\left[1-F\left(z_{t-1}\right)\right] \boldsymbol{\Pi}_{R}(L) \boldsymbol{X}_{t}+F\left(z_{t-1}\right) \boldsymbol{\Pi}_{E}(L) \boldsymbol{X}_{t}+\boldsymbol{\varepsilon}_{t} \\
\boldsymbol{\varepsilon}_{t} & \sim N(0, \Omega) \\
F\left(z_{t}\right) & =\left\{1+\exp \left[-\gamma\left(z_{t}-c\right)\right]\right\}^{-1}, \gamma>0, z_{t} \sim d(0,1)
\end{aligned}
$$

where $\boldsymbol{X}_{t}$ is a set of endogenous variables we aim to model, $\boldsymbol{\Pi}_{R}$ and $\boldsymbol{\Pi}_{E}$ are the VAR coefficients capturing the dynamics of the system during phases of slack and booms (respectively), $\varepsilon_{t}$ is the vector of reduced-form residuals having zero-mean and variance-covariance matrix $\Omega, F\left(z_{t-1}\right)$ is a logistic transition function which captures the probability of being in a boom and whose smoothness parameter is $\gamma, z_{t}$ is a standardized transition indicator, and $c$ is the threshold parameter identifying the two regimes. ${ }^{8}$ Equation-specific constants, omitted for brevity, are also estimated. ${ }^{9}$ In brief, this model combines two linear VARs, one capturing the dynamics of the economy during busts and the other one during booms. The transition from a regime to another is regulated by the smoothness parameter $\gamma$. Large values of $\gamma$ imply abrupt switches from a regime to another, while moderate ones point to regimes of longer duration. ${ }^{10}$

\footnotetext{
${ }^{8}$ Tersvirta, Tjstheim, and Granger (2010) point out that $\gamma$ is not a scale-free parameter. To make it scale free, we follow their suggestion (p. 381 of their book) and standardize the transition indicator so that $z$ is a zero-mean, unitary standard deviation variable. This choice makes it easier to guess a good initial condition for the maximization of the likelihood.

${ }^{9}$ Our Appendix shows that allowing for state-dependent constants does not change our empirical results.

${ }^{10}$ Mumtaz and Theodoridis (2016) point to a different way of modelling the possibly evolving role
} 
Our empirical exercise deals with monthly data to maximize the number of observations for the countries we study while retaining the possibility of studying the impact of EPU uncertainty shocks via the indexes developed by Baker, Bloom, and Davis (2016) for the US and Canada. When choosing the number of lags, we have to take into account that nonlinear frameworks are particularly rich in terms of coefficients to estimate. We use two lags, as indicated by the Akaike criterion (based on a linear VAR(p) framework). The autocorrelation functions of the estimated residuals point to no (or weak, at most) serial correlation. Consistently, estimating $\mathrm{AR}(1)$ process for the residuals returns insignificant coefficients. ${ }^{11}$ As transition indicator, we employ a standardized moving average of the growth rate of a real activity indicator, industrial production in our case, in line with other STVAR-based empirical analysis of the US business cycle (see, among others, Auerbach and Gorodnichenko (2012), Bachmann and Sims (2012), Caggiano, Castelnuovo, and Groshenny (2014), Berger and Vavra (2014), Nodari (2014), Caggiano, Castelnuovo, Colombo, and Nodari (2015), and Figueres (2015)). ${ }^{12}$ Conditional on our choice for $z_{t}$, we jointly estimate the parameters $\left\{\boldsymbol{\Pi}_{R}, \boldsymbol{\Pi}_{E}, \boldsymbol{\Omega}, \gamma, c\right\}$ of model (1)-(3) via conditional maximum likelihood as suggested by Tersvirta, Tjstheim, and Granger (2010). ${ }^{13}$

Modeled vector. We model the Canadian economy with the following vector of US and Canadian observables: $\boldsymbol{X}_{t}=\left[E P U_{t}^{U S}, E P U_{t}, \overline{\Delta I P}_{t}, u_{t}, \pi_{t}, R_{t}, \Delta \epsilon_{t}\right]^{\prime}$. The variable $E P U_{t}^{U S}$ is the US EPU uncertainty index constructed by Baker, Bloom, and

played by uncertainty shocks with an application for the US in which impulse responses are allowed to be time-dependent. A comparison between state- and time-dependent effects of economic policy uncertainty spillovers is material for future research.

${ }^{11}$ The correlograms are available in our Appendix. The estimated coefficients ( $\mathrm{p}$-values robust to heteroskedasticity) of the $\mathrm{AR}(1)$ processes of our estimated residuals mentioned in the text read as follows: US EPU $=-0.01(0.92)$; Canada $\mathrm{EPU}=0.00(0.97)$; Canada IP $=-0.01(0.90)$; Canada unemployment rate $=-0.05(0.32)$; Canada inflation rate $=-0.01(0.87)$; Canada policy rate $=0.02$ (0.79); Canada/US real exchange rate $=-0.02(0.77)$.

${ }^{12}$ We employ a backward-looking moving average of the month-by-month growth rate of industrial production featuring eighteen terms. The number of moving average terms is determined by maximizing the correlation between our transition variable and the dating of Canadian recessions as defined by the Economic Cycle Research Institute ( https://www.businesscycle.com/ ). Our Appendix shows that our results are-robust to two alternative transition indicators, a moving average of the real GDP growth rate and the common factor computed via a principal component analysis which considers the growth rates of industrial production and real GDP and the rates of unemployment and employment.

${ }^{13} \mathrm{An}$ alternative to modeling a smooth transition from a regime to another with an observable indicator would be to model the switch by estimating a latent factor process as in the context of a different - although related - regime switching model (for an extensive presentation, see Hamilton (2016)). We prefer using an observable to determine the regimes in our model (conditional on the estimated values of the logistic function $F\left(z_{t}\right)$ ) to have a cleaner connection with the theoretical and empirical literature cited in the Introduction and in Section 2, which motivates the asymmetric dynamics of the unemployment rate over the business cycle. 
Davis (2016). All the remaining variables in the vector $\boldsymbol{X}_{t}$ refer to the Canadian economy. In particular, $E P U_{t}$ stands for the Canadian uncertainty index, $\overline{\triangle I P}_{t}$ stands for the eighteen-term moving average of the monthly growth rate of industrial production (percentualized and annualized), $u_{t}$ is the unemployment rate, $\pi_{t}$ stands for CPI inflation (y-o-y percentualized growth rate of the monthly index), $R_{t}$ is the policy rate, while $\Delta \epsilon_{t} \equiv \pi_{t}^{U S}+\Delta s_{t}^{C A N, U S}-\pi_{t}^{C A N}$ is the growth rate of the bilateral real exchange rate between Canada and the US constructed by considering the inflation rates in the two countries and combining it with $\Delta s_{t}^{C A N, U S}$, which is the y-O-y growth rate of the Canada/US nominal exchange rate. ${ }^{14}$ Modeling the moving average of industrial production directly in the vector facilitates tracking the evolution of the Canadian business cycle conditional on an US EPU shock. An alternative would be to estimate a model with the month-on-month growth rate of industrial production and construct a boom/bust indicator by externally computing such moving average and its feedback on the endogenous variables of the system. Given the theoretical equivalence of these two ways to go, we decided to model the moving average directly because of its computational simplicity.

We consider the sample January 1985 - October 2014. The start date is dictated by the availability of the Canadian EPU index produced by Baker, Bloom, and Davis (2016), which we use here to make sure that spikes in the US EPU index deliver information over and above the one delivered by abrupt changes in the Canadian one. ${ }^{15}$ The end date is justified by the availability of the EPU historical index for the United States when we started this project. The EPU indices were downloaded from the http://www.policyuncertainty.com/ website. All remaining data were downloaded from the Federal Reserve Bank of St. Louis' website.

Identification. We identify a shock to the US EPU index by assuming a lowertriangular structure of the variance-covariance matrix of the estimated residuals $\Omega$. This implies that shocks to the US economic policy uncertainty index are allowed to affect all Canadian indicators contemporaneously, while the contemporaneous feedback effect going from shocks occurring in Canada to the US EPU index is ruled out. This is a sensible assumption for at least three reasons. First, block-exogeneity is typically

\footnotetext{
${ }^{14}$ The Canadian EPU index is constructed by Baker, Bloom, and Davis (2016) by searching keyword terms such as "spending", "policy", "deficit", "budget", "tax", "regulation", and "central bank" in six different newspapers: The Gazette, The Globe and Mail, Canadian Newswire, The Ottawa Citizen, The Toronto Star, and The Vancouver Sun. The Canadian policy rate is the immediate rates: Less than 24 hours: Central Bank rates for Canada.

${ }^{15}$ In February 1991, the Bank of Canada officially adopted an inflation target. Our results are robust to the employment of the sample 1991:M2-2014:M10 (evidence available upon request).
} 
assumed when modeling small-open economies as Canada. Our restriction is consistent with (in fact, less restrictive than) block-exogeneity. Second, a recent paper by Carriero, Clark, and Marcellino (2018b) provides evidence in favor of a contemporaneous zero impact of business cycle indicators on macroeconomic uncertainty. Finally, Section 4 documents that our results are robust to: i) using an uncertainty dummy which focuses on jumps in uncertainty clearly specific to the US economy, and ii) ordering US and Canadian EPU indices last in the vector.

Linearity test. We test if a nonlinear framework provides us with a statistically better representation of the covariance structure of the data $\boldsymbol{X}_{t}$ relative to a standard linear multivariate framework. Tersvirta and Yang (2014) propose a Lagrange Multiplier test of the null hypothesis of linearity vs. a specified non-linear alternative that is exactly the logistic STVAR framework with a single transition variable. The Lagrange Multiplier statistic is 241.12 , with a p-value equal to 0.00 , which clearly points to the rejection of the null hypothesis of linearity of the model. Details on this test are reported in our Appendix.

\section{EPU spillovers: Empirical evidence}

This Section reports our main empirical findings. We begin by describing the identified US EPU shocks. We then show the estimated probability of slack for Canada according to our model. Finally, we report the GIRFs of the Canadian macroeconomic indicators to an uncertainty shock coming from the United States.

EPU shocks. We identify US EPU shocks by orthogonalizing the residuals $\varepsilon_{t}$ in (1) via a Cholesky-decomposition of the variance-covariance matrix $\Omega$. Since we place the US EPU index first in the vector $\boldsymbol{X}_{t}$, this identification scheme implies that Canadian variables cannot exert a contemporaneous impact on the US uncertainty index. This assumption is weaker than the block-exogeneity assumption usually entertained when working with a small-open economy model for Canada, and let the data free to speak as regards possible feedbacks from Canada to the United States.

Figure 1 plots the estimated series of the US EPU shocks. Vertical lines identify upward spikes in this series that can be interpreted as "large" uncertainty shocks. ${ }^{16}$ We give all these spikes an interpretation based on historical facts, which we report in Table 1. Some spikes regard monetary or fiscal policy related events, like the large

\footnotetext{
${ }^{16}$ These large shocks are identified as positive realizations of the US EPU shocks estimated with our baseline model (and displayed in Figure 1) larger than two standard deviations.
} 
interest rates cuts in early 2008 and the discussions on the budget and the fiscal cliff in 2011 and 2012. These are shocks which we associate to domestic (US) economic conditions, and are likely to be exogenous to the Canadian business cycle. All these events can potentially increase the uncertainty on how economic policy will operate in the future in the US and, as such, represent important drivers behind firms' and households' economic decisions, that eventually affect real activity, both domestically and in countries which are strictly interconnected to the United States, Canada in first place. A few spikes relate to events like the Gulf War I in 1991, the invasion of Iraq in 2003, and the acceleration of the Global Financial Crises in 2008, which can be classified as "global" (i.e., non-US only) events. Our Section on robustness checks document that our results are robust to shocks identified with a US EPU dummy which considers only US related events.

Correlation with other US shocks. We check if our estimated US EPU shocks are correlated with other macroeconomic shocks proposed by the literature (for a similar exercise, see Carriero, Clark, and Marcellino (2018a)). Following Ramey (2016), we focus on monetary, fiscal, and technology shocks. Moreover, given the relevance of credit supply shocks during the Great Recession, we also consider shocks to the excess bond premium as in Gilchrist and Zakrajšek (2012). Overall, we consider eight macroeconomic shocks, i.e., two monetary policy shocks (Romer and Romer (2004) and Barakchian and Crowe (2013)), one financial shock (Gilchrist and Zakrajšek (2012)), two fiscal shocks (fiscal spending news shocks à la Ramey (2011) and tax news shocks as in Mertens and Ravn (2011), with the choice of focusing on the news components being justified by their relevance in the fiscal policy literature), and three technology shocks, i.e., total factor productivity (TFP) shocks, marginal efficiency of investment (MEI) shocks, and investment-specific technology (IST) shocks, all by Justiniano, Primiceri, and Tambalotti (2011). Table 2 collects the correlations with our US EPU shock. None of these shocks is found to significantly correlate with ours. We see this evidence as consistent with our US EPU disturbances as being genuine economic policy uncertainty shocks.

Probability of being in a slack period. Figure 2 plots the estimated probability $[1-F(z)]$ of being in a negative phase of the business cycle for Canada and contrasts it with the 1990-92 and 2008-09 recessions as dated by the Economic Cycle Research Institute (ECRI). Our estimated logistic function for Canada detects both recessions. The delay with which these two deep downturns are tracked is due to the backward-looking nature of the transition indicator we use. Conditional on our estimated threshold $\widehat{c}$, 
our model classifies as recession any date $t$ for which $z_{t}<\widehat{c}$, which in turn implies $\left[1-F\left(z_{t}\right)\right]>0.5{ }^{17}$ This leads us to classify about $18 \%$ of the observations in the sample as recessions, a larger fraction than the $12 \%$ the ECRI business cycle classification suggests. This is mainly due to the fact that our logistic function also points to a deep downturn in the early 2000s, which is not classified as a recession by the ECRI. As explained in detail in our Appendix, the reason for this discrepancy is the following. The early 2000s saw Canada experience a drop in industrial production as large as the one experienced during the two ECRI recessions in our sample. However, labor market indicators pointed to a strong downturn, but not to a clear recession. ${ }^{18}$ Hence, while the early 1990s and the 2008-09 periods clearly featured strong and converging signals in favor of a recession, the early 2000s looked more like a severe downturn. In light of this evidence, our analysis should be interpreted as focusing on phases of growth of industrial production above vs. below the estimated threshold, more than on official "expansions" and "recessions". No matter what the classification one uses is, the share of observations in recessions is larger than $10 \%$, which is the recommendation given by Hansen (1999) to achieve econometric identification in all states. Longer samples do not necessarily guarantee the presence of such minimum number of observations per state. For instance, the sample 1985:M1-2018:M7 (which we use in a robustness check documented in our Appendix, and whose last observation is justified by the availability of industrial production for Canada) is associated to $10.47 \%$ of observations in recessions according to the ECRI classification, and just $8.48 \%$ according to the Howe classification. ${ }^{19}$ This is the reason why we prefer to stick to the 1985-2014 sample as baseline. Importantly, our results are robust to the employment of the 1985-2018 sample.

GIRFs. Figure 3 plots the nonlinear impulse responses of a selected subset of

\footnotetext{
${ }^{17}$ The estimated value of $\widehat{c}$ is consistent with a threshold value for the non-standardized transition variable of -1.34. This implies that our model defines as recession any period $t$ in which the eighteenterm moving average of the monthly growth rate of industrial production has been less than $-1.34 \%$.

${ }^{18}$ The Canadian unemployment rate went up from $6.8 \%$ to $8.1 \%$ from January 2000 to the end of 2001. The variation (difference between these two rates) reads $1.3 \%$. Differently, the unemployment rate jumped from $7.8 \%$ to $10.5 \%$ in the $1988-1991$ period (difference: $2.7 \%$ ) and from $6.1 \%$ to $8.6 \%$ during the Global Financial Crisis (difference: $2.5 \%$ ).

${ }^{19} \mathrm{We}$ are aware of two official datings of the business cycle for Canada. The first one is the one provided by the ECRI, and it is available at https://www.businesscycle.com/ecri-businesscycles/international-business-cycle-dates-chronologies . The second one is provided by the C.D. Howe Institute, and it is available here: https://www.cdhowe.org/council/business-cycle-council . While following slightly different procedures for the dating of the business cycle, these Institutes point to very similar datings of the Canadian business cycle. Our choice of the ECRI dating is due to internal consistency, which regards the fact that we will later use the same source for dating the UK business cycle.
} 
Canadian macroeconomic variables to a one-standard deviation shock to the US EPU shock, along with $68 \%$ confidence bands computed with the bootstrap-after-bootstrap methodology proposed by Kilian (1998). ${ }^{20}$ We focus on unemployment and industrial production as real activity indicators, and inflation and the policy rate because of their policy-relevance. Several comments are worth making. First, there is significant evidence of a spillover effect going from the US to Canada during phases of slack. An unexpected hike in the US economic policy uncertainty index triggers an increase in the Canadian unemployment rate, a decrease in industrial production, and a significant response of inflation and the policy rate. Second, the response of unemployment and industrial production is clearly asymmetric. In particular, the response of real activity is strong and statistically relevant during busts, while it is economically much more modest in booms. Third, differently from unemployment, industrial production displays an abrupt drop, a quick rebound, and a prolonged (but temporary) overshoot when the shock hits in a phase of slack. This pattern is in line with the one predicted, for real activity indicators, by Bloom's (2009) partial equilibrium model featuring labor and investment non-convex adjustment costs. Differently, the reaction of industrial production is insignificant when the shock hits in expansions. Fourth, the response of inflation is found to be different in the two states not only quantitatively but also qualitatively. The response of the growth rate of domestic CPI is negative, and persistently so, in periods of slack, a behavior consistent with a demand-driven interpretation of price formation. Vice-versa, a positive short run reaction is detected when uncertainty hits during booms. This result may find its rationale in the behavior of firms operating in an environment facing price and wage stickiness. As pointed out by Mumtaz and Theodoridis (2015), firms in this environment may optimally decide to increase their prices to avoid getting stuck with "too costly" contracts, i.e., sub-optimally high real wages. Most likely, the different response of the inflation rate in the two states is the reason why the policy rate suggests a prolonged easing in recessions and a short-lived tightening in expansions. As documented by Figure 4, these responses are statistically different between states. ${ }^{21}$

\footnotetext{
${ }^{20}$ Our GIRFs are computed by considering all realizations (and the corresponding initial conditions) of our transition indicator below/above the estimated threshold as busts/booms. Our Appendix shows that our results are robust to selecting initial conditions corresponding to more "extreme" realizations of the business cycle which, without doubt, can be classified as belonging to the "busts"/"booms" regimes. For an example in the literature of this "extreme events" analysis, see Caggiano, Castelnuovo, Colombo, and Nodari (2015).

${ }^{21}$ To account for the correlation between the impulse responses in the two states, the differences plotted in Figure 4 are computed conditional on the same set of bootstrapped residuals. The empirical
} 


\section{Robustness checks}

We check the robustness of our baseline results along four different dimensions: i) the identification of US-related EPU shocks; ii) the inclusion of proxies of US financial and economic uncertainty; iii) the control for US first moment shocks; iv) the control for commodity and oil price fluctuations.

US EPU dummy. The results shown in Section 4 rely on the use of the EPU index for the US as an observable in the VAR, whose orthogonalized residuals are interpreted as US shocks external to Canada. However, some of the spikes of the EPU index can be attributed to events connected to global pressure. Davis (2016) proposes a Global Economic Policy Uncertainty (GEPU) index constructed by considering a GDP-weighted average of national EPU indices for 16 countries that account for twothirds of global output. The national EPU indices are constructed following Baker et al.'s (2016) newspaper-based approach. In our sample, the GEPU index rises sharply in correspondence of the Asian Financial Crisis, the 9/11 terrorist attacks, the USled invasion of Iraq in 2003, the Global Financial Crisis in 2008-09, and the European immigration crisis. $^{22}$ Some global events are indeed picked up by the estimated US EPU shock plotted in Figure 1. In particular, the Gulf War I spike, the one corresponding to the Iraq invasion, and the one identifying the peak of uncertainty due to the Global Financial Crisis can be considered as global shocks, more than domestic (US) shocks.

How relevant are these global shocks for our result? We address this question by constructing a US EPU dummy which takes value 1 only for those events that can be safely classified as US-specific. Table 1 lists the US-specific EPU shocks we consider. This dummy is then included in our STVAR in lieu of the US EPU index. In this way, we check the solidity of our baseline results to the employment of US-specific shocks only.

Uncertainty ordered last. Our baseline model assumes that both the US and the Canadian EPU indicators are not contemporaneously influenced by any of the shocks originating in Canada. This assumption appears to be plausible and fully consistent with the block-exogeneity approach typically employed when it comes to modeling the interaction between a large economy like the United States and a small-open economy like Canada (see, e.g., Justiniano and Preston (2010)). Moreover, Carriero, Clark, and Marcellino (2018b) provide evidence in favor of macroeconomic uncertainty as a driver of

density of the difference is estimated using 500 realizations per each horizon of interest.

${ }^{22}$ The correlation between the GEPU index and the US EPU one is very high and equal to 0.84 . We do not model them jointly in our vector to avoid issues related to multicollinearity. 
the business cycle in the US. Hence, a fortiori, one would think of it as being exogenous to the Canadian business cycle. However, while this assumption is typically entertained for aggregates like inflation and output, less is known on the interconnections between economic policy uncertainty in neighboring countries strictly related by intense trading flows. To understand how relevant this assumption is for our results, we then run a check in which we order US and Canada EPU last, i.e. after the block of Canadian macro variables. This allows both the US and the Canadian uncertainty indices to react on impact to Canadian first moment shocks.

Financial Uncertainty. The EPU index constructed by Baker, Bloom, and Davis (2016) is meant to capture economic policy-related spikes in uncertainty. One concern with our analysis is to what extent we are capturing effects coming from spikes in economic policy uncertainty as opposed to different aspects of economic uncertainty. We tackle this issue by alternatively augmenting our VAR with two measures of financial uncertainty. The first one is the VXO, which is the S\&P 100 implied volatility index computed by the Chicago Board Options Exchange. The VXO index captures the evolution of the volatility of expected stock market returns, and has been used since Bloom (2009) as a proxy of financial uncertainty in applied macroeconomic investigations. ${ }^{23}$ Adding the VXO to our VAR allows us to control for movements in a financial measure of uncertainty, which also spikes up in correspondence of events like, e.g., 9/11 which drove the US EPU index up. ${ }^{24}$ The idea of our robustness check is then to obtain a purged measure of the US EPU shocks, which is not driven by financial uncertainty. Following Baker, Bloom, and Davis (2016), we order the VXO after the US EPU index and before the Canadian block of variables in our vector. This ordering minimizes the risk of getting biased impulse responses due to the imposition of the zero contemporaneous feedback going from economic policy uncertainty (and, more in general, macroeconomic uncertainty) to financial uncertainty (Carriero, Clark, and Marcellino (2018b)). Moreover, Granger causality tests suggest strong evidence supporting causality from the US EPU to the VXO (p-value: 0.03), while reverse causality is just mildly supported (p-value: 0.10 ). The second measure we consider is the measure of financial

\footnotetext{
${ }^{23}$ A close measure is the S\&P 500 Volatility index computed by the Chicago Board Options Exchange, which is known as the VIX. The correlation between the VIX and the VXO at a monthly frequency in the sample January 1990 (first month of availability of the VIX)-October 2014 is 0.99. We prefer to work with the VXO because it goes back in time to January 1986.

${ }^{24}$ As stressed by Stock and Watson (2012), uncertainty shocks and liquidity/financial risk shocks are highly correlated, which makes their separate identification challenging. For contributions aiming at separating uncertainty and financial shocks, see Christiano, Motto, and Rostagno (2014), Caldara, Fuentes-Albero, Gilchrist, and Zakrajšek (2016), Furlanetto, Ravazzolo, and Sarferaz (2017).
} 
uncertainty recently proposed by Ludvigson, Ma, and Ng (2019). Such measure is constructed following the data-rich approach modeling the expected volatility of a large number of financial series proposed by Jurado, Ludvigson, and Ng (2015), who model a broader macroeconomic uncertainty measure combining financial and real economic indicators. The Ludvigson, Ma, and $\mathrm{Ng}$ (2019) measure of uncertainty, which focuses on financial indicators, is arguably more exogenous (for evidence in this sense, see Angelini, Bacchiocchi, Caggiano, and Fanelli (2019) and Ludvigson, Ma, and Ng (2019)). For the same reason indicated above, we model this measure after the US EPU index, whose shocks have already been shown to be uncorrelated with financial shocks in the previous Section.

Economic Uncertainty. Another possibility is that of confounding economic policy uncertainty with the broader concept of economic uncertainty. Baker, Bloom, and Davis (2016) construct an overall Economic Uncertainty (EU) index by dropping all terms related to policy in the keyword-based search they conduct. ${ }^{25}$ We then add the overall EU index to our VAR to isolate the policy component of the US EPU shocks over and above a more general measure of economic uncertainty. As before, we follow Baker, Bloom, and Davis (2016) and order the EU index just after the US EPU index.

Excess bond premium. Gilchrist and Zakrajšek (2012) propose a micro-founded measure of excess bond premium (EBP). Such measure of credit spread is constructed by controlling for the systematic movements in default risk on individual firms. Consequently, the EBP isolates the cyclical changes in the relationship between measured default risk and credit spreads. Gilchrist and Zakrajšek (2012) show that the EBP has predictive power for a number of US real activity indicators. Moreover, when embedded in a VAR to quantify the effects of a credit shock, unexpected jumps in EBP are found to be associated to temporary but economically significant recessions and deflations. A recent paper by Grtz, Tsoukalas, and Zanetti (2016) shows the importance of the excess bond premium as a predictor of present and future real activity, in particular for predicting the effects of future (news) shocks. Caldara, Fuentes-Albero, Gilchrist, and Zakrajšek (2016) and Alessandri and Mumtaz (2018), show that the effects of uncertainty shocks are amplified when financial stress is high. To capture the possibility that movements in EBP caused some of the movements in the US EPU index, we add

\footnotetext{
${ }^{25}$ The EU index is available here: http://www.policyuncertainty.com/Replication_Files.zip . A full documentation on the construction of this index is provided in Baker, Bloom, and Davis (2016), who also compare the characteristics of the EPU and EU indices. The EU series is quarterly. We then construct a monthly counterpart via quadratic-match average, which performs a proprietary local quadratic interpolation of the low frequency data to fill in the high observations.
} 
EBP on top of our baseline vector to control for credit shocks.

Factor-Augmented STVAR. Our baseline model indicates that a substantial chunk of the volatility of the Canadian unemployment rate could be due to a second moment shock eoming from the United States. However, a number of US first moment shocks - among others, technology, fiscal, and monetary policy shocks - are likely to be at play and influence the Canadian economy. While the separate identification of each of these shocks is left to future research, it is clearly important to control for a composite of these first moment disturbances to minimize the probability of an upward bias as regards the contribution of US EPU shocks on the Canadian unemployment. To tackle this issue, we proceed as follows. First, we use principal component analysis to extract common factors from the 134 monthly US indicators included in the FRED-MD dataset, recently compiled by McCracken and $\mathrm{Ng}(2016) .{ }^{26}$ Second, we consider the first factor in terms of contribution to the variance of the series belonging to the FRED-MD and add it as first variable to our baseline vector. This two-step procedure is meant to emulate the Factor-Augmented VAR (FAVAR) approach proposed by Bernanke, Boivin, and Eliasz (2005) for the identification of a monetary policy shock.

Commodity/oil prices. Canada is a resource-rich country which exports oil and other commodities. As documented by Charnavoki and Dolado (2014), energy products represented $23.5 \%$ of total merchandise exports in 2010, while other basic products and materials related to the agriculture sector, forestry and mining accounted for about $40 \%$ of those exports. Charnavoki and Dolado (2014) investigate the relevance of shocks to commodity prices for the Canadian economy via a structural dynamic factor model. They measure commodity prices by computing the common factor of a range of indices for energy, food, agricultural raw materials, base metals, and fertilizers, and find commodity price shocks to be an important driver of the Canadian business cycle. Among commodity prices, oil price represents a particularly relevant factor for business cycle fluctuations in a small open economy like Canada both for its direct impact on Canadian exports and for its potential indirect impact via its effects on the US economy. Hamilton (2003) shows that oil price fluctuations have preceded all US recessions included in our sample. Hence, oil prices may very well be an important driver of both uncertainty and real activity in the US and Canada. Our baseline framework does not feature commodity and/or oil prices. We then run three robustness checks in which we enrich our baseline vector with, alternatively, Charnavoki and Dolado's (2014) global commodity price factor, and with two measures of oil prices: the producer price index

\footnotetext{
${ }^{26}$ The database can be downloaded from the website http://research.stlouisfed.org/econ/mccracken/sel/.
} 
for crude petroleum and refiner acquisition cost for imported oil. ${ }^{27}$

Figure 5 displays the outcome of our robustness checks. A few comments are in order. First, our baseline finding is robust across all robustness checks. In particular, it is clearly robust to the employment of our US EPU dummy, something that points to a spillover effect actually due to US EPU shocks. Second, shocks other than the US EPU one evidently affect the Canadian unemployment rate. The baseline response of unemployment is dampened in most scenarios, with a reduction of the peak response of about $40 \%$ in a variety of models. In particular, the models accounting for first moment US shocks, broad economic uncertainty, and fluctuations in oil and commodity prices are those that return the lowest peak reactions of unemployment to an EPU shock. Third, out of the above mentioned models, those incorporating information on EU, oil, and commodity prices predict the peak of unemployment to come after a few months and imply the lowest integral of the response of unemployment. Differently, the model featuring first moment shocks predict unemployment to peak after one year and a somewhat slower speed of convergence towards the steady state. Fourth, the across-model heterogeneity of unemployment responses observed in busts is larger than in booms. This suggests that model misspecification due to the omission of relevant macroeconomic indicators is likely to be more important when studying US EPU spillovers in the context of Canadian busts, compared to booms.

Heteroskedasticity. The STVAR we employ allows for state dependence of the coefficient matrices but not of the covariance matrix. One may wonder to what extent this constraint is relevant for our results. We investigate this issue by following the approach proposed by Auerbach and Gorodnichenko (2012) and employed in the context of uncertainty shocks by Caggiano, Castelnuovo, and Groshenny (2014). Such approach allows the covariance matrix to be state dependent. In doing so, we treat the transition indicator as endogenous and compute GIRFs accordingly as in Caggiano, Castelnuovo, Colombo, and Nodari (2015). To facilitate the convergence toward the global maximum

\footnotetext{
${ }^{27}$ As regards Charnavoki and Dolado's (2014) measure, we compute the common factor of the commodity price indexes as documented in their paper. The database constructed by Charnavoki and Dolado that contains the series employed to construct such common factor is downloadable from the website of the American Economic Journal: Macroeconomics. The producer price index has been downloaded from the St. Louis Fed FRED website, while the refiner acquisition cost has been downloaded from the Energy Administration Information website. The reason for using both measures, alternatively, in our robustness checks is due to the possibly different effects of oil shocks obtained by using these different price measures, as highlighted by Hamilton (2003, 2011) and Kilian and Vigfusson (2011) respectively. For this reason, in Figure 5 we label the producer price index as "oil Hamilton" and the refiner acquisition cost as "oil Kilian". Both series have been deflated using the CPI. Results are robust to using nominal instead of real prices (evidence available upon request).
} 
of the likelihood function, we calibrate the slope parameter of the logistic function $\gamma$ and the threshold parameter $c$ to their baseline values. For the sake of brevity, we relegate details on the model - which can be also be found in Caggiano, Castelnuovo, Colombo, and Nodari (2015) - in our Appendix. Figure 6 displays the GIRFs produced with this more flexible model, which confirm that our baseline results are robust to allowing for heteroskedasticity in the reduced form residuals. As in the baseline case, such GIRFs are statistically different between the two states (evidence available in the Appendix for the sake of brevity).

\section{EPU shocks: Contribution and transmission mech- anism}

The results documented so far speak in favor of the fact that variations in the US EPU index can be associated to fluctuations in real activity, inflation, and the shortterm interest rate in Canada. But how strong is this relationship? And what is the transmission mechanism, really? We answer these questions by considering, in turn, the results coming from a forecast error variance decomposition (FEVD) analysis and from two counterfactual exercises aiming at isolating the role of the Canadian EPU vis-àvis the role of bilateral trade for the transmission of US EPU shocks to the Canadian economy.

\subsection{Generalized Forecast Error Variance Decomposition}

We conduct the forecast error variance decomposition analysis by implementing the algorithm by Lanne and Nyberg (2016), who propose a generalized version of the forecast error variance decomposition for multivariate nonlinear models. Table 3 collects the figures related to the forecast error variance decomposition analysis conditional to a 24-month horizon. ${ }^{28}$ The first three rows of each panel report the contribution of US EPU, Canada EPU, and monetary policy shocks in our baseline specification, while the fourth row reports the contribution of US EPU shocks in the model augmented with economic uncertainty. ${ }^{29}$ We begin by looking at the FEVD conditional to economic busts obtained with our baseline specification. A number of considerations are in order.

\footnotetext{
${ }^{28} \mathrm{~A}$ FEVD analysis focusing on a 12-month horizon delivers very similar results, which are available upon request.

${ }^{29}$ The reason for reporting results from the model augmented with economic uncertainty is that, among all models reported in the robustness checks section, this is the one that returns a less pronounced response of unemployment.
} 
First, as shown by the first row of the Table, in bad times US EPU shocks explain $26 \%$ of the volatility of the Canadian unemployment rate. Hence, EPU spillovers are quantitatively important to explain the dynamics of a key labor market variable such as the unemployment rate. Interestingly, movements in the Canadian EPU index explain about $23 \%$ of the Canadian unemployment rate. These numbers points to EPU shocks coming from the US as being as important as domestic Canadian EPU shocks, a result consistent with Klößner and Sekkel's (2014) evidence pointing to policy spillovers from the United States to Canada. Moreover, uncertainty is important in general, given that it is responsible for about $49 \%$ of the variation in unemployment at a 2 -year horizon. Second, looking at the FEVD in booms shows that the role of uncertainty is relevant in bad times only. Indeed, these figures dramatically drop to 9\% (US EPU shocks) and 5\% (Canadian EPU shocks) when it comes to explaining unemployment during expansionary phases of the Canadian business cycle. A similar result holds true as regards industrial production, with uncertainty shocks explaining about 8\% (US EPU) and 15\% (Canadian EPU) in busts, and about $2 \%$ and $4 \%$ in booms. ${ }^{30}$ Finally, the contribution of external economic policy uncertainty shocks to the volatility of inflation, the shortterm interest rate, and the bilateral real exchange rate reads, respectively, $14 \%, 17 \%$, and $14 \%$ in busts while it ranges from $4 \%$ to $6 \%$ in booms. Again, independently of the state of the economy, these figures are found to be fairly in line with the contribution of the Canadian EPU shocks.

Another result of our FEVD analysis regards the drivers of the EPU indices employed in our analysis. As reported in Table 3, about $62 \%$ of the volatility of the US EPU index in busts is driven by its own innovation, while the contribution of the Canadian EPU is about $8 \%$. Looking at booms, Canadian EPU explains an even lower share of the US EPU (about 3\%), which is instead mostly explained (about $72 \%$ of total volatility) by its own shock. ${ }^{31}$ Differently, the contribution of US EPU innovations to the volatility of the Canadian EPU index is $32 \%$ in busts and $31 \%$ in booms. This information is consistent with Granger causality tests conducted with a linear bivariate

\footnotetext{
${ }^{30}$ Admittedly, reverse causality going from the Canadian business cycle to the Canadian EPU could be in place. For the US, evidence on the possible exogeneity of macroeconomic uncertainty has been provided by both Carriero, Clark, and Marcellino (2018b) and Section 3 of this paper (the exercise correlating US EPU shocks with some existing measures of macroeconomic shocks). Unfortunately, for Canada neither a study à la Carriero, Clark, and Marcellino (2018b) nor established measures of macroeconomic shocks is readily available.

${ }^{31}$ Notice that here we are referring to the volatility of the EPU indexes, not to that of the innovations to such indexes. Such innovations, which are those we use to compute the GIRFs documented in the previous Section and the FEVD reported in this Section, are - by construction - exogenous under the assumption of our VAR being rich enough from an informational standpoint.
} 
framework modeling the two EPU indices. Such tests support the causality running from the US EPU index to the Canadian one at any conventional level (the p-value of the null hypothesis of non-causality is 0.00 ), while they reject the causality running from the Canadian EPU index to the US one (p-value: 0.36). ${ }^{32}$ This result supports a novel reading of the role of big countries like the US as regards the dynamics of small neighboring countries like Canada. Small open economies like Canada can be affected not only via the already well-known effects related to first-moment shocks like variations in technology or changes in macroeconomic policies, but also via a novel contagion channel which hinges upon second moments.

It is of interest to compare the contribution of uncertainty shocks to those of monetary policy shocks. ${ }^{33}$ The figures collected in Table 3 clearly point to a much smaller role played by monetary policy shocks as regards unemployment, with a contribution of about $7 \%$ during downturns (about one fourth compared to external uncertainty shocks) and about $3 \%$ in booms (vs. $9 \%$ by US EPU shocks'). The contribution of monetary policy shocks to the volatility of inflation reads $16 \%$ in busts and $14 \%$ in booms, and it is larger than that of uncertainty shocks, above all during expansions. Interestingly, the overall contribution of uncertainty shocks to the dynamics of the real exchange rate in busts is about $36 \%$, much larger than the $5 \%$ due to monetary policy shocks. This gap is much smaller in booms, with the former shocks being responsible for about $9 \%$ of the variance of the real exchange rate against a contribution of about $3 \%$ by monetary policy shocks. Not surprisingly, the main driver of the short-term interest rate is monetary policy shocks. All in all, our results clearly point to uncertainty shocks (both external and domestic) as relevant drivers of the Canadian business cycle, at least when compared to monetary policy disturbances.

Finally, we check if our findings are robust to the controls we employed to produce the GIRFs documented in Figure 5. Following Baker, Bloom, and Davis (2016), we take the modelembedding the broad definition of Economic Uncertainty as a reference. Table 3 documents the contribution of the US EPU shocks to the volatility of the variables in our baseline vector conditional on the EU control. Not surprisingly, the figures corresponding to this scenario point to a more limited role played by US EPU shocks

\footnotetext{
${ }^{32}$ We model a linear $\operatorname{VAR}(6)$ as suggested by the Akaike lag-length criterion. Moreover, a simple regression of the Canadian uncertainty index on a constant and lagged US EPU returns an adjusted $R^{2}$ of 0.33 , a signal of high predictive power of the US EPU index on the Canadian counterpart.

${ }^{33}$ As discussed in Section 1, we interpret uncertainty shocks as second moment shocks although they affect the generalized impulse responses via the VAR conditional mean, an impact which is usually associated to first moment shocks.
} 
for the volatility of the Canadian unemployment rate. However, such contribution is still as large as $13 \%$ in busts, while it is a sixth of it $(2 \%)$ in booms. This exercise suggests two things. First, US EPU shocks are likely to be a composite of pure policyrelated uncertainty shocks and more general economic uncertainty shocks in models that do not feature a broader measure of uncertainty, like the EU indicator. Second, our results still hold when this control is added to our baseline vector. Importantly, our Appendix shows that our main results are robust across all the different models discussed above.

\subsection{Transmission mechanism: The uncertainty spillover chan- nel}

The results of our FEVD analysis point to the possibility of an international "EPU spillover channel" linking the United States and Canada. In particular, one can conjecture the former country to be a big player whose economic policy uncertainty may lead neighboring countries like Canada to record subsequent increases in domestic uncertainty, and via this channel affect domestic business cycle indicators, in particular unemployment. An equally plausible transmission channel from US EPU to real activity in Canada would work via trade. Uncertainty in the US would depress domestic consumption and investment, hence US demand of imports from Canada, and via this channel increase unemployment in Canada. The conjecture that fluctuations in uncertainty occurring in the US both foster uncertainty and depress net exports in Canada is confirmed by the impulse responses of Canadian EPU and net exports to a shock to the US EPU index, obtained with our STVAR model augmented with a measure of bilateral trade balance, which are shown in Figure $7 .^{34}$ The left panel of Figure 7 plots the Canadian EPU impulse response during economic busts. The Canadian index significantly increases after a US EPU shock, before quickly going back to the pre-shock level. The right panel of Figure 7 plots the response of Canadian net exports to US EPU shocks. As one can see, net exports display a significant, short-lived decrease as a consequence of a jump in US economic policy uncertainty. ${ }^{35}$ This gives us a broader pic-

\footnotetext{
${ }^{34}$ The series of US imports from Canada (IMPCA) and US exports to Canada (EXPCA) are downloaded from the FRED database. Real net exports are defined as the difference between imports and exports divided by US CPI. The variable is ordered last in our VAR. The estimated VAR includes also economic uncertainty, ordered second.

${ }^{35}$ The analysis is aimed at describing the transmittion channel of US EPU shocks in Canada during periods of slack. Therefore, for the sake of clarity of exposition, we do not plot the responses of Canadian EPU and net exports in booms. However, the full set of responses in booms and busts, available upon request, confirms our baseline findings: both Canadian EPU and net exports react
} 
ture of the effects of a shock to the level of US economic policy uncertainty on Canada: a US policy uncertainty shock triggers an increase in Canadian policy uncertainty, a decrease in Canadian net exports to the US, and a temporary downturn of real activity. One possible interpretation of these facts is that there might be two alternative, not mutually exclusive, transmission mechanisms at work simultaneously, i.e., one that transmits US EPU shocks to the Canadian real economy via uncertainty spillovers, the other that works via trade.

We shed light on the relative role played by the Canadian EPU index and bilateral trade in transmitting US policy-related shocks by conducting two counterfactual simulations. In the first one, the Canadian EPU index is not allowed to respond to systematic movements in US EPU, while net exports are left free to react. In the second one, it is Canadian net exports that do not react to US EPU fluctuations, while Canadian EPU is left free to respond. If the main driver of unemployment fluctuations in Canada is the response of Canadian economic policy uncertainty to US EPU, and not US economic policy uncertainty per se or via its impact on net exports, then the first counterfactual should return a more moderate responses of the Canadian unemployment rate to a US EPU shock compared to both the baseline response of unemployment and the counterfactual one obtained by switching off the "trade channel".

Figure 8 summarizes the results obtained by estimating the baseline version of our STVAR as in Section 4, augmented with both economic uncertainty, ordered second, and net exports, ordered last. The Figure reports, conditional to economic busts, the response of Canada's unemployment rate to a one standard deviation US EPU shock in four scenarios: the full model; the model without net exports; the counterfactual response obtained by muting only the response of Canada EPU to US EPU; the counterfactual response obtained by muting only the response of net exports to US EPU. Two main findings arise. First, adding net exports to the baseline model leaves the peak response of unemployment virtually unaffected, while it makes its response milder at larger horizons. Second, the peak response of unemployment is halved in the counterfactual scenario in which the Canadian EPU index does not respond to movements in US EPU, while it remains virtually unchanged in the counterfactual scenario where net exports do not react to systematic movements in US EPU. ${ }^{36}$ Overall, the results from both counterfactuals suggests that the negative spillover of US economic policy more strongly to US EPU shocks in recessionary times.

${ }^{36}$ If anything, shutting down net exports makes the response of unemployment more persistent at longer horizons. This finding is consistent with Charnavoki and Dolado (2014), who document a Dutch-disease type of effect at business cycle frequencies for Canada. 
uncertainty shocks on real activity in Canada is mainly due to the reaction of Canadian economic policy uncertainty, while the trade channel plays a minor role. We interpret this evidence as consistent with the "economic policy uncertainty spillovers channel".

\section{EPU spillovers: The case of the UK}

The results obtained so far document a significant economic uncertainty spillover effect originating in the United States for the Canadian economy. It is of interest to investigate whether this finding is specific to Canada, or rather it applies also to other economies, not necessarily as much integrated with the US as Canada is. One interesting alternative case is provided by the UK for two main reasons. First, the UK is a much larger economy compared to Canada, so in principle less prone to spillovers of shocks originating in other countries. According to the IMF, the UK GDP in 2015 was equal to 2,849,345 millions of US\$, almost twice the size of Canadian GDP, which was equal to 1,552,386 millions (again, measured by US\$). Second, despite sharing similar characteristics with the United States, it is far from being as much trade integrated as Canada. In terms of bilateral trade with the US, in $201511 \%$ of UK total exports were imported by the Unites States ( $74 \%$ the share for Canada), and $6.7 \%$ of UK imports came from the United States (55\% the share for Canada).

We then replicate the analysis conducted in Section 4 for Canada with UK data. We estimate our nonlinear framework (1)-(3) to model the following vector: $\boldsymbol{X}_{t}=$ $\left[E P U_{t}^{U S}, E P U_{t}, \overline{\Delta I P}_{t}, u_{t}, \pi_{t}, R_{t}, \Delta \epsilon_{t}\right]^{\prime}$, where $E P U_{t}^{U S}$ is the US EPU uncertainty index, while the remaining variables refer to the United Kingdom. The definition of the variables follows the one of the US-Canada case. ${ }^{37}$ To facilitate the comparison of this case with our baseline case, we use the very same sample, i.e., 1985:M1-2014:M10. Conditional on the same metric used for Canada, we employ a MA(12) process for the growth rate of industrial production as indicator of the business cycle because of its highest correlation with the ECRI recessions with respect to a variety of alternative moving averages. Such correlation is basically the same as the one between the MA(18) process and the ECRI recessions. We choose to employ the MA(12) process to handle a more parsimonious framework.

Figure 9 plots the response of industrial production, unemployment, inflation and

\footnotetext{
${ }^{37}$ For the United Kingdom, the policy rate is the discount rate. The correlation between this rate and the 3-month rate on UK Treasury securities reads 0.99 in our sample. All series were downloaded from the Federal Reserve Bank of St. Louis' website.
} 
the policy rate to a one-standard deviation shock in US EPU conditional on booms and busts in the United Kingdom. An unexpected increase in US economic policy uncertainty triggers a negative response in UK real activity, both in unemployment and in industrial production. As for the case of Canada, such response is quantitatively larger if the UK economy is already in a period of slack. The response of inflation is hardly significant. Differently, we find the response of the policy rate to be negative and significant in both states of the economy.

Figure 10 plots the difference between the impulse responses. The differences in the reaction of industrial production and the policy rate are found to be statistically significant at $68 \%$ confidence level. For unemployment, although the mass of the distribution of the difference is clearly tilted toward the positive plane (which is associated to a larger response of unemployment in recessions), the between-state difference is not statistically significant. However, a clearly significant difference emerges when the longer 1959:M1-2014:M10 sample is employed. This result, shown in our Appendix for brevity, is likely to be due to the higher number of recessions in this longer sample, which lead to more precise estimates. Our results (for both samples) are confirmed by an alternative analysis in which we use a dummy similar to the one used in the US-Canada case to identify US EPU shocks which are not connected to the global cycle (evidence available in our Appendix). Overall, the results for the UK confirm that economic policy uncertainty shocks originating in the US can spillover onto other economies and trigger an asymmetric response of real activity depending on the stance of the business cycle. Hence, evidence in favor of the economic policy uncertainty spillovers channel documented in the previous Section is not confined to a small-open economy like Canada that is linked to the US by an intense trading activity. Indeed, we find that it could very well be a relevant transmission channel of US EPU shocks also for bigger and more trade-independent economies (in terms of relationship with the US) such as the United Kingdom

\section{Conclusions}

We investigate the spillover effects of a jump in US economic policy uncertainty for the Canadian business cycle. Using a nonlinear (Smooth-Transition) VAR, we find that such effects are present, significant, and asymmetric over the Canadian business cycle. In particular, our empirical model points to a strong evidence of spillovers during periods of busts experienced by the countries that receive the external uncertainty 
shocks. The macroeconomic responses in these two states are found to be different from a statistical and economic standpoint. Counterfactual simulations conducted by freezing the response of the Canadian economic policy uncertainty index to US EPU signal the existence of an "economic policy uncertainty spillover channel", i.e., spikes in US economic policy uncertainty foster uncertainty in Canada and, via this channel, lead to a temporary slowdown of Canada's real activity. This result is shown to be robust to the possible presence of a simultaneous "trade channel", working via fluctuations in bilateral trade. Finally, similar analysis conducted for the UK confirms that US EPU shocks are likely to be among the drivers of unemployment when bad times are in place also in economies that are relatively larger and less integrated with the United States.

From a policy perspective, our evidence suggests that uncertainty about future policy actions in influential countries like the US may be costly not only for such countries but can importantly spillover on to small-open economies like Canada. As discussed by Davis (2015), the large increase in the number of norms and regulations that the US economy has experienced for several years now is likely to have increased the level of policy-related uncertainty. Davis (2015) and Baker, Bloom, and Davis (2016) call for a clear, simple, and easy to manage regulatory system, a simple tax system, and predictable, timely, and clearly communicated policies. Thinking of the advantages of having economically sound commercial partners, our results suggest that the pay-off for the US of implementing the policies suggested by Davis (2015) and Baker, Bloom, and Davis (2016) may be larger than those typically estimated when considering the US case in isolation.

From a modeling standpoint, we see this results as pointing to the relevance of US economic policy uncertainty as a driver of non-US business cycles. Other measures of uncertainty have recently been proposed by the literature. In particular, financial and macroeconomic uncertainty measures à la Jurado, Ludvigson, and Ng (2015) and Ludvigson, Ma, and Ng (2019) have recently been produced by Redl (2017) for the UK, by Grimme and Stckli (2018) for Germany, and by Meinen and Rhe (2017) for some Euro area countries. We see the employment of these measures in a nonlinear analysis discerning between different phases of the business cycle as a promising avenue for future research.

\section{References}

Alessandri, P., And H. Mumtaz (2018): "Financial Regimes and Uncertainty Shocks," Journal of Monetary Economics, forthcoming. 
Angelini, G., E. Bacchiocchi, G. Caggiano, and L. Fanelli (2019): "Uncertainty Across Volatility Regimes," Journal of Applied Econometrics, 34(3), 437-455.

Auerbach, A., and Y. Gorodnichenko (2012): "Measuring the Output Responses to Fiscal Policy," American Economic Journal: Economic Policy, 4(2), 1-27.

Bachmann, R., S. Elstner, and E. Sims (2013): "Uncertainty and Economic Activity: Evidence from Business Survey Data," American Economic Journal: Macroeconomics, 5(2), 217-249.

Bachmann, R., And E. Sims (2012): "Confidence and the transmission of government spending shocks," Journal of Monetary Economics, 59(3), 235-249.

Baker, S., N. Bloom, and S. J. Davis (2016): "Measuring Economic Policy Uncertainty," Quarterly Journal of Economics, 131(4), 1539-1636.

Barakchian, S. M., and C. Crowe (2013): "Monetary policy matters: Evidence from new shocks data," Journal of Monetary Economics, 60(8), 950-966.

Belke, A., AND T. Osowski (2018): "International Effects of Euro Area versus U.S. Policy Uncertainty: A FAVAR Approach," Economic Inquiry, forthcoming.

Benigno, G., P. Benigno, and S. Nistic (2012): "Risk, Monetary Policy and the Exchange Rate," in D. Acemoglu and M. Woodford (eds.): NBER Macroeconomics Annual, vol. 26, University of Chicago Press, 247-309.

Benigno, P., And A. Ricci (2011): "The Inflation-Output Trade-Off with Downward Wage Rigidities," American Economic Revew, 101(4), 1436-1466.

Berger, D., And J. Vavra (2014): "Measuring How Fiscal Shocks Affect Durable Spending in Recessions and Expansions," American Economic Review Papers and Proceedings, 104(5), 112-115.

Berger, T., S. Grabert, and B. Kempa (2016): "Global and Country-Specific Output Growth Uncertainty and Macroeconomic Performance," Oxford Bulletin of Economics and Statistics, 78(5), 694-716.

Bernanke, B., J. Boivin, And P. Eliasz (2005): "Measuring Monetary Policy: A Factor Augmented Vector Autoregressive (FAVAR) Approach," Quarterly Journal of Economics, 120(1), 387-422.

Bloom, N. (2014): "Fluctuations in Uncertainty," Journal of Economic Perspectives, 28(2), 153-176.

Bloom, N. (2017): "Observations on Uncertainty," Australian Economic Review, $50(1), 79-84$.

Bloom, N., M. Floetotto, N. Jaimovich, I. Saporta-Eksten, and S. J. TERRY (2018): "Really Uncertain Business Cycles," Econometrica, 86(3), 1031-1065.

Born, B., G. Mller, And J. Pfeifer (2013): "Terms of trade uncertainty and business cycle fluctuations," Universities of Bonn and Mannheim, mimeo.

Born, B., And J. Pfeifer (2014): "Risk Matters: The Real Effects of Volatility Shocks: Comment," American Economic Review, 104(12), 4231-4239. 
Cacciatore, M., and F. Ravenna (2018): "Uncertainty, Wages, and the Business Cycle," HEC Montreal, mimeo.

Caggiano, G., E. Castelnuovo, V. Colombo, and G. Nodari (2015): "Estimating Fiscal Multipliers: News From a Nonlinear World," Economic Journal, 125(584), $746-776$.

Caggiano, G., E. Castelnuovo, and J. M. Figueres (2017): "Economic Policy Uncertainty and Unemployment in the United States: A Nonlinear Approach," Economics Letters, 151, 31-34.

(2018): "Economic Policy Uncertainty Spillovers in Booms and Busts," CESifo Working Paper No. 7086.

Caggiano, G., E. Castelnuovo, and N. Groshenny (2014): "Uncertainty Shocks and Unemployment Dynamics: An Analysis of Post-WWII U.S. Recessions," Journal of Monetary Economics, 67, 78-92.

Caggiano, G., E. Castelnuovo, and G. Nodari (2019): "Uncertainty and Monetary Policy in Good and Bad Times," available at https://sites.google.com/site/efremcastelnuovo/.

CaldarA, D., C. Fuentes-Albero, S. Gilchrist, and E. ZakrajšEK (2016): "The Macroeconomic Impact of Financial and Uncertainty Shocks," European Economic Review, 88, 185-207.

Carriero, A., T. E. Clark, and M. Marcellino (2018a): "Assessing International Commonality in Macroeconomic Uncertainty and Its Effects," Federal Reserve Bank of Cleveland Working Paper No. 18-05.

(2018b): "Endogenous Uncertainty," Federal Reserve Bank of Cleveland Working Paper No. 18-05.

(2018c): "Measuring Uncertainty and Its Impact on the Economy," Review of Economics and Statistics, forthcoming.

Carrire-Swallow, Y., and L. F. Cspedes (2013): "The impact of uncertainty shocks in emerging economies," Journal of International Economics, 90, 316-325.

Casarin, R., C. Foroni, M. Marcellino, and F. Ravazzolo (2018): "Uncertainty Through the Lenses of A Mixed-Frequency Bayesian Panel Markov Switching Model," Annals of Applied Statistics, forthcoming.

Castelnuovo, E., G. Lim, and G. Pellegrino (2017): "A Short Review of the Recent Literature on Uncertainty," Australian Economic Review, 50(1), 68-78.

Castelnuovo, E., and T. D. Tran (2017): "Google it up! A Google Trends-based Uncertainty Index for the United States and Australia," Economics Letters, 161, 149-153.

Cesa-Bianchi, A., M. H. Pesaran, and A. Rebucci (2018): "Uncertainty and Economic Activity: A Multi-Country Perspective," NBER Working Paper No. 24325.

Charnavoki, V., and J. J. Dolado (2014): "The Effects of Global Shocks on Small Commodity-Exporting Economies: Lessons from Canada," American Economic Journal: Macroeconomics, 6(2), 207-237. 
Christiano, L., R. Motto, and M. Rostagno (2014): "Risk Shocks," American Economic Review, 104(1), 27-65.

Colombo, V. (2013): "Economic policy uncertainty in the US: Does it matter for the Euro Area?," Economics Letters, 121(1), 39-42.

Creal, D. D., and C. Wu (2017): "Monetary Policy Uncertainty and Economic Fluctuations," International Economic Review, forthcoming.

Davis, S. J. (2015): "Regulatory Complexity and Policy Uncertainty: Headwinds of Our Own Making," Document prepared to accompany remarks delivered at he Hillsdale College Free Market Forum on "Markets, Government, and the Common Good" in Omaha, Nebraska on 15-17 October 2015.

(2016): "An Index of Global Economic Policy Uncertainty," NBER Working Paper No. 22740.

Dibooglu, S., And W. Enders (2001): "Do Real Wages Respond Asymmetrically to Unemployment Shocks? Evidence from the U.S. and Canada," Journal of Macroeconomics, 23, 495-515.

Faccini, R., H. Mumtaz, And P. Surico (2016): "International fiscal spillovers," Journal of International Economics, 99, 31-45.

Fernndez-Villaverde, J., P. Guerrón-Quintana, J. F. Rubio-Ramírez, and M. URIBE (2011): "Risk Matters: The Real Effects of Volatility Shocks," American Economic Review, 101, 2530-2561.

Ferrara, L., And P. Gurin (2018): "What Are The Macroeconomic Effects of HighFrequency Uncertainty Shocks?," Journal of Applied Econometrics, forthcoming.

Figueres, J.M. (2015): "News on State-Dependent Fiscal Multipliers: The role of Confidence," University of Padova Marco Fanno Working Paper No. 202.

Furlanetto, F., F. Ravazzolo, and S. Sarferaz (2017): "Identification of financial factors in economic fluctuations," Economic Journal, forthcoming.

Gilchrist, S., and E. ZakrajŠEK (2012): "Credit Spreads and Business Cycle Fluctuations," American Economic Review, 102(4), 1692-1720.

Gourio, F., M. Siemer, and A. Verdelhan (2013): "International Risk Cycles," Journal of International Economics, 89(2), 471-484.

Grimme, C., And M. Stckli (2018): "Measuring Macroeconomic Uncertainty in Germany," CESifo Forum, 19(1), 46-50.

Grtz, C., J. D. Tsoukalas, and F. Zanetti (2016): "News Shocks under Financial Frictions," Working Paper 2016 15, Business School - Economics, University of Glasgow.

Hamilton, J. D. (2003): "What Is an Oil Shock?," Journal of Econometrics, 113, 363-398.

(2016): "Macroeconomic Regimes and Regime Shifts," in: J.B. Taylor and H. Uhlig (eds.): Handbook of Macroeconomics, Elsevier Science, forthcoming. 
HANDLEy, K. (2014): "Exporting under trade policy uncertainty: Theory and evidence," Journal of International Economics, 94(1), 50-66.

HANDLEY, K., AND N. Limo (2015): "Trade and Investment under Policy Uncertainty: Theory and Firm Evidence," American Economic Journal: Economic Policy, 7(4), $189-222$.

(2017): "Policy Uncertainty, Trade and Welfare: Theory and Evidence for China and the United States," American Economic Review, 107(9), 2731-2783.

Hansen, B. E. (1999): “Testing for Linearity," Journal of Economic Surveys, 13(5), $551-576$.

Istrefi, K., And S. MouabBi (2017): "Subjective Interest Rate Uncertainty and the Macroeconomy: A Cross-country Analysis," Journal of International Money and Finance, forthcoming.

Jurado, K., S. C. Ludvigson, And S. NG (2015): "Measuring Uncertainty," American Economic Review, 105(3), 1177-1216.

Justiniano, A., And B. Preston (2010): "Can structural small open-economy models account for the influence of foreign disturbances?, Journal of International Economics, 81, 61-74.

Justiniano, A., G. E. Primiceri, and A. Tambalotti (2011): "Investment shocks and the relative price of investment," Review of Economic Dynamics, 14(1), 101-121.

Kilian, L. (1998): "Small-Sample Confidence Intervals for Impulse Response Functions," Review of Economics and Statistics, 80, 218-230.

Kilian, L., and R. Vigfusson (2011): "Are the Responses of the U.S. Economy Asymmetric in Energy Price Increases and Decreases?," Quantitative Economics, 2, $419-453$.

KlÖssner, S., And R. SekKel (2014): "International Spillovers of Policy Uncertainty," Economics Letters, 124, 508-512.

Koop, G., M. Pesaran, and S. Potter (1996): "Impulse response analysis in nonlinear multivariate models," Journal of Econometrics, 74(1), 119-147.

Koop, G., And S. Potter (1999): "Dynamic Asymmetries in U.S. Unemployment," Journal of Business and Economic Statistics, 17(3), 298-312.

Kulish, M., And D. ReEs (2011): "The Yield Curve in a Small Open Economy," Journal of International Economics, 85(2), 268-279.

LAnNe, M., AND H. Nyberg (2016): "Generalised Forecast Error Variance Decomposition for Linear and Nonlinear Multivariate Models," Oxford Bulletin of Economics and Statistics, 78, 595-603.

Ludvigson, S. C., S. MA, And S. NG (2019): "Uncertainty and Business Cycles: Exogenous Impulse or Endogenous Response?," New York University and Columbia University, mimeo. 
McCracken, M. W., And S. Ng (2016): "FRED-MD: A Monthly Database for Macroeconomic Research," Journal of Business and Economic Statistics, 34(4), 574589.

Meinen, P., And O. Rhe (2017): "On measuring uncertainty and its impact on investment: Cross-country evidence from the euro area," European Economic Review, 92(C), 161-179.

Mertens, K., and M. O. Ravn (2011): "Understanding the Aggregate Effects of Anticipated and Unanticipated Tax Policy Shocks," Review of Economic Dynamics, $14(1), 27-54$.

Morley, J., And J. Piger (2012): "The Asymmetric Business Cycle," Review of Economics and Statistics, 94(1), 208-221.

Morley, J., J. Piger, And P.-L. Tien (2013): "Reproducing Business Cycle Features: Are Nonlinear Dynamics a Proxy for Multivariate Information?," Studies in Nonlinear Dynamics \& Econometrics, 17(5), 483-498.

Mumtaz, H., And K. Theodoridis (2015): "The International Transmission of Volatility Shocks: An Empirical Analysis," Journal of the European Economic Association, $13(3), 512-533$.

(2016): "The changing transmission of uncertainty shocks in the US: An empirical analysis," Journal of Business and Economic Statistics, forthcoming.

Mumtaz, H., and F. Zanetti (2013): "The Impact of the Volatility of Monetary Policy Shocks," Journal of Money, Credit and Banking, 45(4), 535-558.

NodARI, G. (2014): "Financial Regulation Policy Uncertainty and Credit Spreads in the U.S.," Journal of Macroeconomics, 41, 122-132.

ONG, K. (2018): "Do fiscal spending news shocks generate financial spillovers?," Economics Letters, 164, 46-49.

Ramey, V. A. (2011): "Identifying Government Spending Shocks: It's All in the Timing," Quarterly Journal of Economics, 126(1), 1-50.

(2016): "Macroeconomic Shocks and Their Propagation," in: J.B. Taylor and H. Uhlig (Eds.): Handbook of Macroeconomics, Elsevier Science, 2, 71-162.

REDL, C. (2017): "The Impact of Uncertainty Shocks in the U.K.," Bank of England Staff Working Paper No. 695.

Romer, C., And D. Romer (2004): "A New Measure of Monetary Policy Shocks: Derivation and Implications," American Economic Review, 94(4), 1055-1084.

Rossi, B., And T. SEkhposyan (2015): "Macroeconomic Uncertainty Indices Based on Nowcast and Forecast Error Distributions," American Economic Review Papers and Proceedings, 105(5), 650-655.

Rossi, B., and T. Sekhposyan (2017): "Macroeconomic Uncertainty Indices for the Euro Area and its Individual Member Countries," Empirical Economics, 53(1), $41-62$. 
SchmitT-Grohe, S. (1998): "The International Transmission of Economic Fluctuations: Effects of US Business Cycles on the Canadian Economy," Journal of International Economics, 44, 257-287.

Scotti, C. (2016): "Surprise and Uncertainty Indexes: Real-Time Aggregation of Real-Activity Macro Surprises," Journal of Monetary Economics, 82, 1-19.

Stock, J. H., and M. W. Watson (2012): "Disentangling the Channels of the 2007-2009 Recession," Brookings Papers on Economic Activity, Spring, 81-135.

Tersvirta, T., D. Tustheim, and C. W. Granger (2010): "Modeling Nonlinear Economic Time Series," Oxford University Press, Oxford.

Tersvirta, T., And Y. YAng (2014): "Linearity and Misspecification Tests for Vector Smooth Transition Regression Models," CREATES Research Papers 2014-04, School of Economics and Management, University of Aarhus.

van DiJk, D., T. Tersvirta, And P. H. Franses (2002): "Smooth Transition Autoregressive Models - A Survey of Recent Developments," Econometric Reviews, $21(1), 1-47$.

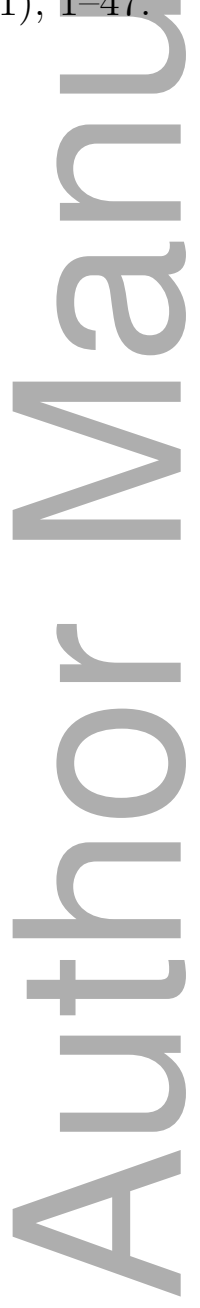




\begin{tabular}{llcc}
\hline \hline \multicolumn{1}{c}{ Date } & \multicolumn{1}{c}{ Event } & Baseline & Dummy \\
\hline Oct. 1987 & Black Monday & $\mathrm{X}$ & $\mathrm{X}$ \\
Jan. 1991 & Gulf War I & $\mathrm{X}$ & \\
Nov. 2000 & Bush election & $\mathrm{X}$ & $\mathrm{X}$ \\
Sep. 2001 & $9 / 11$ & $\mathrm{X}$ & $\mathrm{X}$ \\
Mar. 2003 & Iraq invasion & $\mathrm{X}$ & \\
Jan. 2008 & Large interest rate cuts & $\mathrm{X}$ & $\mathrm{X}$ \\
Sep. 2008 & Lehman Brothers' bankruptcy & $\mathrm{X}$ & $\mathrm{X}$ \\
Oct. 2008 & Global Financial Crisis & $\mathrm{X}$ & \\
July 2010 & Mid-term elections & $\mathrm{X}$ & $\mathrm{X}$ \\
Sep. 2010 & Mid-term elections & $\mathrm{X}$ & $\mathrm{X}$ \\
July 2011 & Debt Ceiling & $\mathrm{X}$ & $\mathrm{X}$ \\
Aug. 2011 & Debt Ceiling & $\mathrm{X}$ & $\mathrm{X}$ \\
Nov. 2012 & Fiscal cliff & $\mathrm{X}$ & $\mathrm{X}$ \\
Oct. 2013 & Government shutdown & $\mathrm{X}$ & $\mathrm{X}$ \\
\hline
\end{tabular}

Table 1: Major US and Global Economic Policy Uncertainty Shocks. Baseline: Dates corresponding to positive realizations of the estimated shocks exceeding 2 standard deviations according to our baseline model. Dummy: Dates selected by focusing on domestic (US) events only.

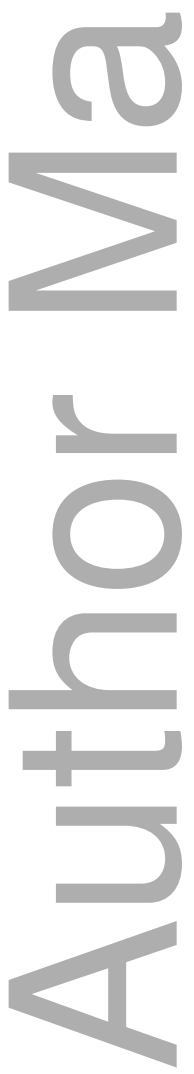




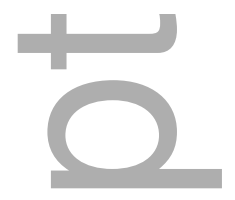

\begin{tabular}{|c|c|c|}
\hline Shock & Sample & Correlation \\
\hline Romer and Romer's (2004) mon. pol. shocks & 1985:M3-2007:M12 & $\begin{array}{l}0.03 \\
(0.56)\end{array}$ \\
\hline Barakchian and Crowe's (2013) mon. pol. shocks & 1985:M12-2008:M6 & $\begin{array}{l}-0.01 \\
(-0.24)\end{array}$ \\
\hline Gilchrist and Zakrajšek's (2012) EBP shocks & 1985:M3-2014:M10 & $\begin{array}{l}0.11 \\
(0.22)\end{array}$ \\
\hline Ramey's (2011) fiscal spending news shocks & 1985:Q1-2013:Q4 & $\begin{array}{l}0.11 \\
(0.15)\end{array}$ \\
\hline Mertens and Ravn's (2012) tax news shocks & 1985:Q1-2007:Q3 & $\begin{array}{l}0.00 \\
(0.99)\end{array}$ \\
\hline Justiniano, Primiceri, and Tambalotti's (2011) TFP shocks & 1985:Q1-2009:Q1 & $\begin{array}{c}-0.09 \\
(0.18)\end{array}$ \\
\hline Justiniano, Primiceri, and Tambalotti's (2011) MEI shocks & 1985:Q1-2009:Q1 & $\begin{array}{l}-0.07 \\
(0.42)\end{array}$ \\
\hline Justiniano, Primiceri, and Tambalotti's (2011) IST shocks & 1985:Q1-2009:Q1 & $\begin{array}{l}0.10 \\
(0.33)\end{array}$ \\
\hline
\end{tabular}

Table 2: Correlation of US EPU uncertainty shocks with selected US macroeconomic shocks. Sample periods indicated in the Table determined by the availability of the other shocks conditional on our baseline sample. EBP, TFP, MEI, and IST stand for excess bond premium, total factor productivity, marginal efficiency of investment, and investment-specific technology, respectively. EBP shocks estimated as the residual of an AR(2) process for EBP. P-values of the t-statistics of the correlation coefficient obtained by regressing the uncertainty shock on the macroeconomic shock and a constant. Variances underlying the t-statistics robust to heteroskedasticity. Samples dictated by data availability. When correlations are computed with shocks available at quarterly frequencies, the last observation in each quarter of the monthly US EPU shocks series is used to convert the shock from monthly to quarterly. Source of all shocks: Valerie Ramey's webpage.

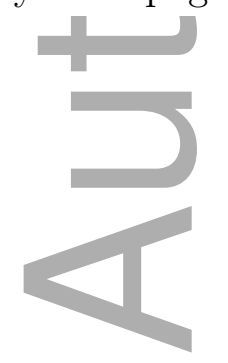




\begin{tabular}{|c|c|c|c|c|c|c|c|c|}
\hline \multirow{2}{*}{\multicolumn{2}{|c|}{ Shock/Variable }} & \multicolumn{7}{|c|}{ Busts } \\
\hline & & $E P U_{t}^{U S}$ & $E P U_{t}$ & $\Delta I P_{t}$ & $u_{t}$ & $\pi_{t}$ & $R_{t}$ & $\Delta \epsilon_{t}$ \\
\hline & & 0.62 & 0.32 & 0.08 & 0.26 & 0.14 & 0.17 & 0.14 \\
\hline & & 0.08 & 0.36 & 0.15 & 0.23 & 0.10 & 0.14 & 0.22 \\
\hline & & 0.04 & 0.06 & 0.07 & 0.07 & 0.16 & 0.51 & 0.05 \\
\hline & $E U$ & 0.35 & 0.15 & 0.03 & 0.13 & 0.08 & 0.05 & 0.05 \\
\hline & & \multicolumn{7}{|c|}{ Booms } \\
\hline Shock/ & Variable & $E P U_{t}^{U S}$ & $E P U_{t}$ & $\Delta I P_{t}$ & $u_{t}$ & $\pi_{t}$ & $R_{t}$ & $\Delta \epsilon_{t}$ \\
\hline & & 0.72 & 0.31 & 0.02 & 0.09 & 0.04 & 0.06 & 0.04 \\
\hline & & 0.03 & 0.44 & 0.04 & 0.05 & 0.05 & 0.09 & 0.05 \\
\hline$\pi_{t}$ & & 0.02 & 0.05 & 0.10 & 0.03 & 0.14 & 0.62 & 0.03 \\
\hline & $E U$ & 0.33 & 0.08 & 0.00 & 0.02 & 0.02 & 0.01 & 0.01 \\
\hline & & \multicolumn{7}{|c|}{ Linear } \\
\hline Shock// & Variable & $E P U_{t}^{U S}$ & $E P U_{t}$ & $\Delta I P_{t}$ & $u_{t}$ & $\pi_{t}$ & $R_{t}$ & $\Delta \epsilon_{t}$ \\
\hline$\widetilde{\varepsilon}^{E P U_{t}^{U S}}$ & & 0.88 & 0.35 & 0.02 & 0.17 & 0.05 & 0.09 & 0.06 \\
\hline$\widetilde{\varepsilon}^{E P U_{t}}$ & & 0.02 & 0.55 & 0.04 & 0.07 & 0.07 & 0.12 & 0.06 \\
\hline$\widetilde{\varepsilon}^{R_{t}}$ & & 0.01 & 0.03 & 0.06 & 0.05 & 0.12 & 0.67 & 0.01 \\
\hline$\widetilde{\varepsilon}^{E P U_{t}^{U S}}$ & $E U$ & 0.45 & 0.15 & 0.01 & 0.02 & 0.01 & 0.02 & 0.00 \\
\hline
\end{tabular}

Table 3: Forecast Error Variance Decomposition: US vs. Canadian EPU Shocks. 2 year-ahead forecast error variance decomposition. The figures reported in the table refer to the point estimates of the baseline model, with the exception of those in the fourth line of each case (Busts, Booms, Linear), which refer to the model with the Economic Uncertainty measure placed after the US EPU index in the vector.

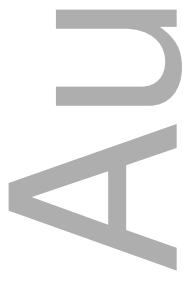




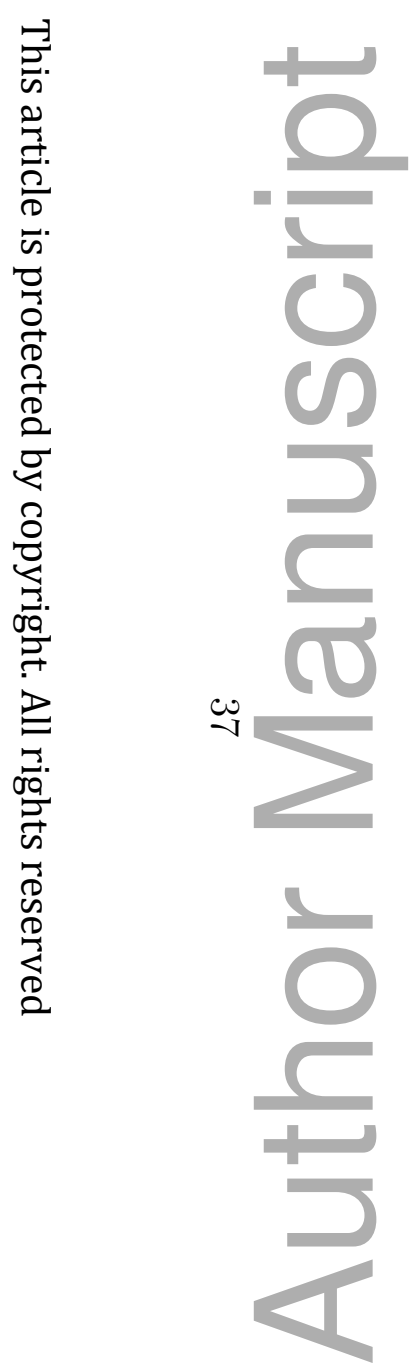

Figure 1: US EPU shocks. Blue line: US EPU shocks estimated with the US-Canada STVAR as explained in the text. Black vertical lines: Realizations of the shock larger than two standard deviations. Grey vertical bars: Canadian recessions as dated by the ECRI. 


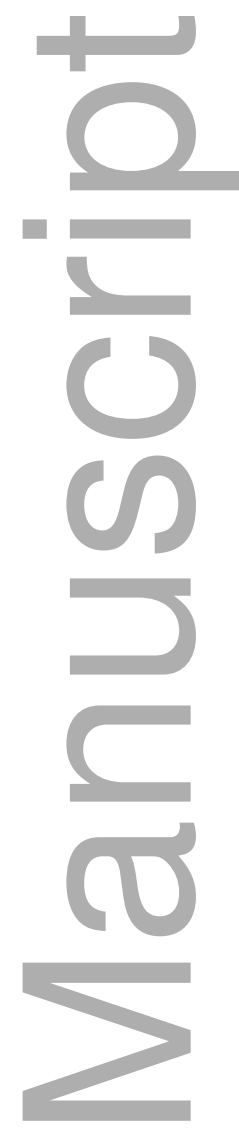

Figure 2: Probabilities of Economic Busts for Canada as Estimated by the STVAR model. Sample: 1985:M1-2014:M10. Function [1-F(z)] estimated jointly with the baseline STVAR model. Transition indicator $z$ : 18-month moving average of the monthly growth rate of the Canadian industrial production index. Grey vertical bars indicate recessions as dated by the Economic Cycle Research Institute. 


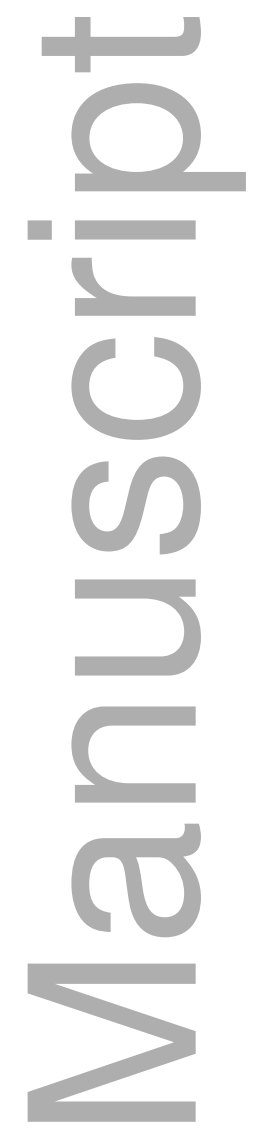

Figure 3: Effects of a shock to the US EPU Index on the Canadian economy. Sample: 1985:M1-2014:M10. Median generalized impulse responses to a one-standard deviation shock to the US EPU index hitting the Canadian economy in busts (red solid line) and booms (blue dashed-dotted line). $68 \%$ confidence intervals identified via shaded areas (busts) and dashed blue lines (booms). Transition indicator for Canada: 18-term moving average of the monthly growth rate of the Canadian industrial production.

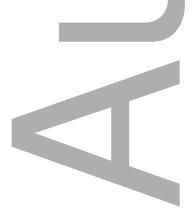




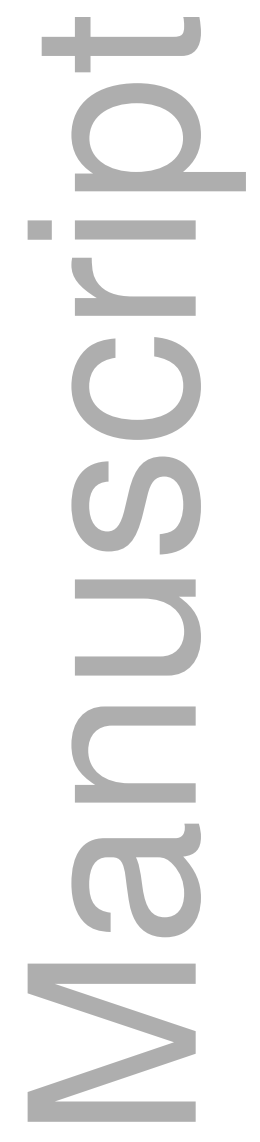

Figure 4: Effeets of a shock to the US EPU Index on the Canadian economy: Difference between states. Sample: 1985:M1-2014:M10. Differences between median generalized impulse responses in busts and booms to a one-standard deviation shock to the US EPU Index. Median realizations identified via black lines, $68 \%$ confidence intervals identified via shaded areas. Transition indicator for Canada: 18-term moving average of the monthly growth rate of the Canadian industrial production.

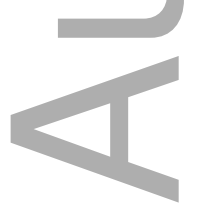




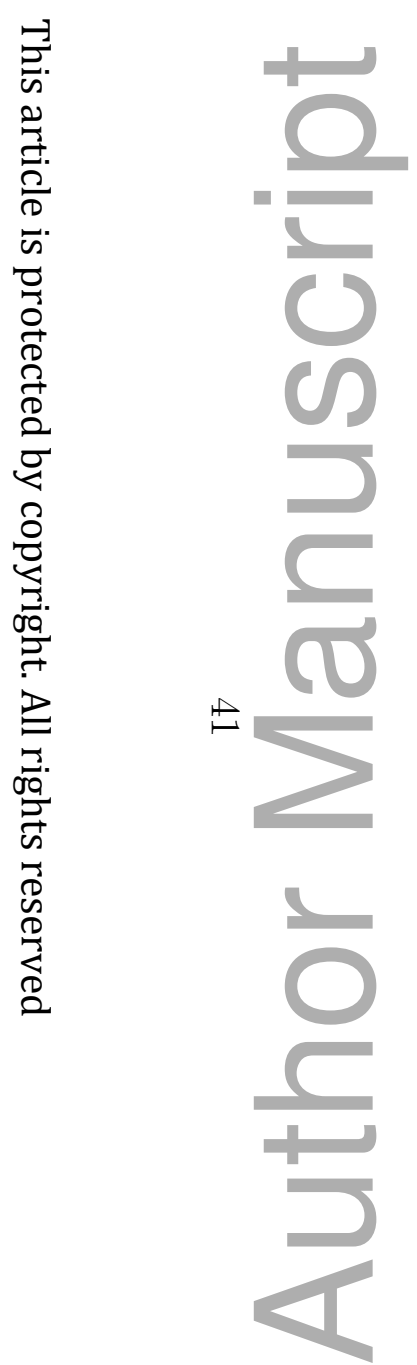

Figure 5: Response of the Canadian unemployment rate to an EPU shock originating in the US: Robustness checks. Responses of Canadian unemployment to a one standard deviation US EPU shock for the models discussed in Section 5 . 


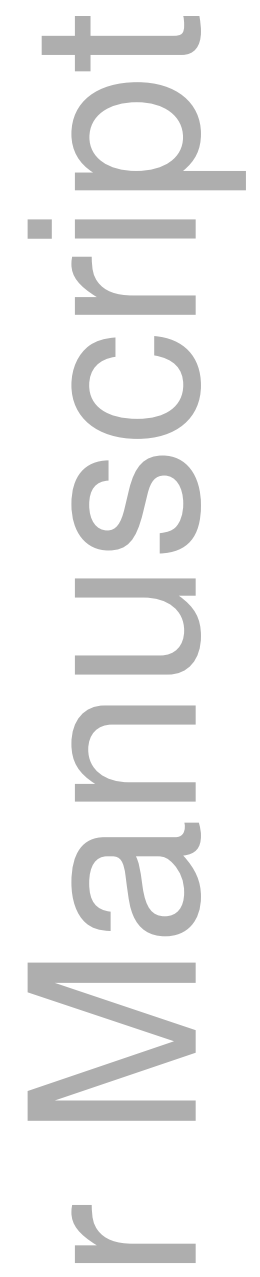

Figure 6: Effects of a shock to the US EPU Index on the Canadian economy: Role of Heteroskedasticity. Sample: 1985:M1-2014:M10. Statistical model as in Caggiano, Castelnuovo, and Groshenny (2014). Median generalized impulse responses to a one-standard deviation shock to the US EPU index hitting the Canadian economy in busts (red solid line) and booms (blue dashed-dotted line). 68\% confidence intervals identified via shaded areas (busts) and dashed blue lines (booms). Transition indicator for Canada: 18-term moving average of the monthly growth rate of the Canadian industrial production.

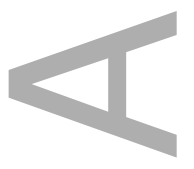




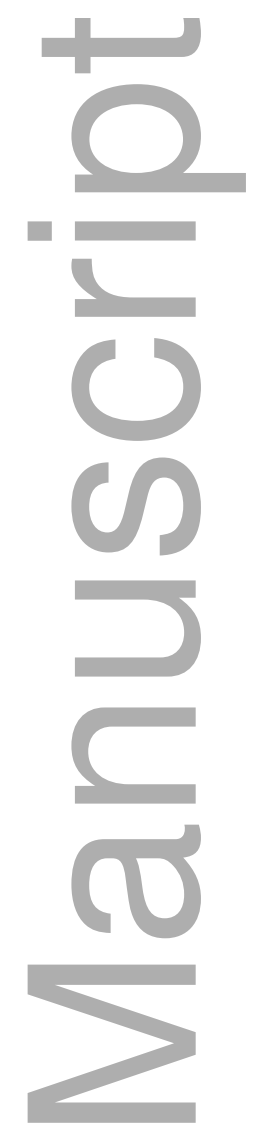

Figure 7: Responses of Canadian EPU and net exports to US EPU shocks. Generalized impulse responses to a one-standard deviation shock to the US EPU index hitting the Canadian economy in busts. 68\% confidence bands denoted by shaded areas. Left panel: Canadian EPU. Right panel: net exports. Transition indicator for Canada: 18-term moving average of the monthly growth rate of the Canadian industrial production index. Model featuring economic uncertainty ordered second and net exports ordered last in the vector.

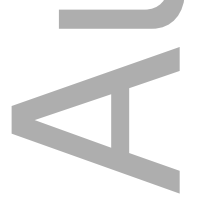




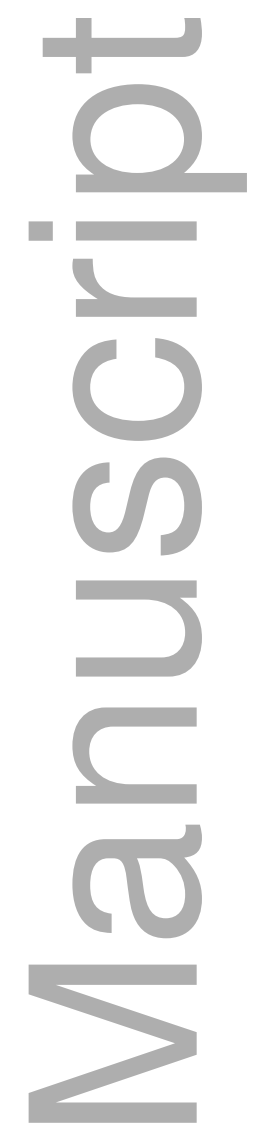

Figure 8: Effects of a shock to the US EPU index on the Canadian economy: Role of the uncertainty and trade channels. Sample: 1985:M1-2014:M10. Generalized impulse responses of the Canadian unemployment rate in busts. Solid green line: response of unemployment in the baseline model without net exports (labeled "Baseline"). Dashed-dotted brown line: response of unemployment in the baseline model including net exports (labeled "Net Exports"). Dashed purple line: couterfactual impulse response of unemployment obtained by zeroing the coefficients of Canada EPU to US EPU in the equation modeling Canada EPU (labeled "No resp. of CAN EPU"). Dotted black line: couterfactual impulse response of unemployment obtained by zeroing the coefficients of net exports to US EPU in the equation modeling net exports (labeled "No resp. of CAN EPU"). All models featuring Economic Uncertainty ordered second in the vector as a control. 


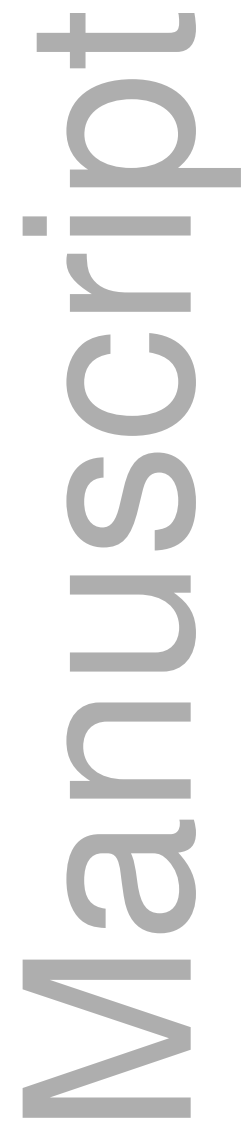

Figure 9: Effects of a shock to the US EPU index on the UK economy. Sample: 1985:M1-2014:M10. Median generalized impulse responses to a one-standard deviation shock to the US EPU index hitting the UK economy in busts (red solid line) and booms (blue dashed-dotted line). 68\% confidence intervals denoted by shaded areas (busts) and dashed blue lines (booms). Transition indicator for the UK: 12-term moving average of the monthly growth rate of the UK industrial production index.

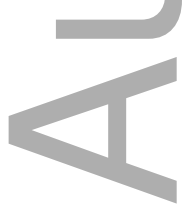




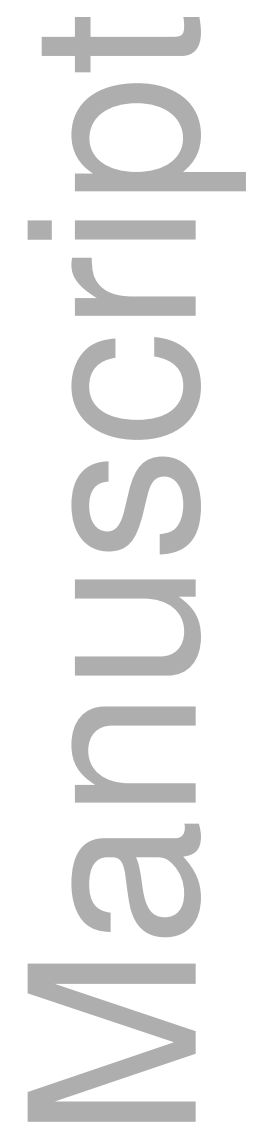

Figure 10: Effects of a shock to the US EPU index on the UK economy: Difference between states. Sample: 1985:M1-2014:M10. Differences between median generalized impulse responses in booms and busts to a one-standard deviation shock to the US EPU index. Median realizations denoted with black lines, $68 \%$ confidence intervals denoted with shaded areas. Transition indicator for the UK: 12-term moving average of the monthly growth rate of the UK industrial production index. 


\section{University Library}

\section{- M M N E R VA A gateway to Melbourne's research publications}

Minerva Access is the Institutional Repository of The University of Melbourne

Author/s:

Caggiano, G;Castelnuovo, E;Figueres, JM

Title:

Economic Policy Uncertainty Spillovers in Booms and Busts

Date:

2020-02-02

Citation:

Caggiano, G., Castelnuovo, E. \& Figueres, J. M. (2020). Economic Policy Uncertainty Spillovers in Booms and Busts. Oxford Bulletin of Economics and Statistics, 82 (1), pp.125-155. https://doi.org/10.1111/obes.12323.

Persistent Link:

http://hdl.handle.net/11343/253829 